\title{
Erosion as a driving mechanism of intracontinental mountain growth
}

\author{
J. P. Avouac \\ Laboratoire de Géophysique, Bruyères-Le-Châtel, France \\ E. B. Burov \\ Laboratoire de Gravimétrie et Géodynamique, Institut de Physique du Globe de Paris
}

\begin{abstract}
In nature, mountains can grow and remain as localized tectonic features over long periods of time ( $>10$ m.y.). By contrast, according to current knowledge of lithospheric rheology and neglecting surface processes, any intracontinental range with a width that exceeds that which can be supported by the strength of the lithosphere should collapse within a few tens of millions of years. For example, assuming a quartz-dominated crustal rheology, the relief of a range initially $3 \mathrm{~km}$ high and $300-400 \mathrm{~km}$ wide is reduced by half in about $15 \mathrm{~m} . \mathrm{y}$. as a result of lateral spreading of its crustal root. We suggest that surface processes might actually prevent such a "subsurface collapse." Removal of material from topographic heights and deposition in the foreland oppose spreading of the crustal root and could eventually drive a net influx of material toward the orogeny. We performed a set of numerical experiments in order to validate this hypothesis. A section of a lithosphere, with a brittle-elasto-ductile rheology, initially loaded by a mountain range is submitted to horizontal shortening and to surface processes. If erosion is intense, material is removed more rapidly than it can be supplied by crustal thickening below the range, and the topography is rapidly smoothed. For example, a feature $3 \mathrm{~km}$ high and $300-400$ $\mathrm{km}$ wide is halved in height in about $15 \mathrm{~m} . \mathrm{y}$. for an erosion coefficient $k=10^{3} \mathrm{~m}^{2} / \mathrm{yr}$ (the erosion rate is of the order of a few $0.1 \mathrm{~mm} / \mathrm{yr}$ ). This regime might be called "erosional collapse." If erosion is not active enough, the crustal root spreads out laterally and "subsurface collapse" occurs. In the third intermediate regime, removal of the material by erosion is dynamically compensated by isostatic rebound and inward flow in the lower crust so that the range can grow. In this "mountain growth" regime the range evolves toward a characteristic graded shape that primarily depends on the erosion law. The erosion rate may be high (e.g., $0.5-0.9 \mathrm{~mm} / \mathrm{yr}$ ), close to the rate of tectonic uplift (e.g., $0.7-1.1 \mathrm{~mm} / \mathrm{yr})$, and few times higher than the rate of topographic uplift $(0.15-0.2 \mathrm{~mm} / \mathrm{yr})$. These experiments show that surface processes can favor localized crustal shortening and participate in the development of an intracontinental mountain. Surface processes must therefore be taken into account in the interpretation and modeling of long-term deformation of continental lithosphere. Conversely, the mechanical response of the lithosphere must be accounted for when large-scale topographic features are interpreted and modeled in terms of geomorphologic processes.
\end{abstract}

\section{Introduction}

Intracontinental mountain ranges are gencrally interpreted to have resulted from localized crustal thickening in response to horizontal shortening. The growth and maintenance of such topographic features within continents might be taken to indicate that the strength of the crust exceeds the deviatoric stresses associated with slopes of the topography and of the Moho. Yet, laboratory experiments indicate that at the pressure and temperature conditions of the lower crust, most crustal rocks should flow easily [e.g., Brace and Kohlstedt, 1980; Wang et al., 1994]. Irregularities of the topography and of the Moho should therefore be relaxed by viscoplastic flow in the ductile lower crust and decay with time [Kusznir and Matthews, 1988; Gratton, 1989; Bird, 1991]. Consider for example the

Copyright 1996 by the American Geophysical Union.

Paper number 96JB01344.

$0148-0227 / 96 / 96 \mathrm{JB}-01344 \$ 09.00$
Tien Shan, which is, except for the Himalayas, the largest and most active intracontinental range in the world (Figure 1). The range is $300-400 \mathrm{~km}$ wide in its central portion, with a mean elevation of about $3500 \mathrm{~m}$, in a zone of relatively thick and tectonized crust (Moho depths from 50 to $70 \mathrm{~km}$ ) [c.g., Avouac et al., 1993]. A simple dimensional analysis [Gratton, 1989] as well as numerical simulations [Bird, 1991] show that the topography of such a range should be reduced by half in a few million years or at most tens of millions of years, depending on the assumed rheology of the lower crust. Only the short topographic wavelengths, typically less than a few tens of kilometers, that can be supported by the strength of the upper crust would be maintained over geological periods of time. In addition, surface processes might be thought to contribute to an even more rapid smoothing of the topography. Altogether, in the absence of strain localization processes a portion of a continental crust submitted to horizontal shortening is expected to thicken homogeneously so that no mountain should 


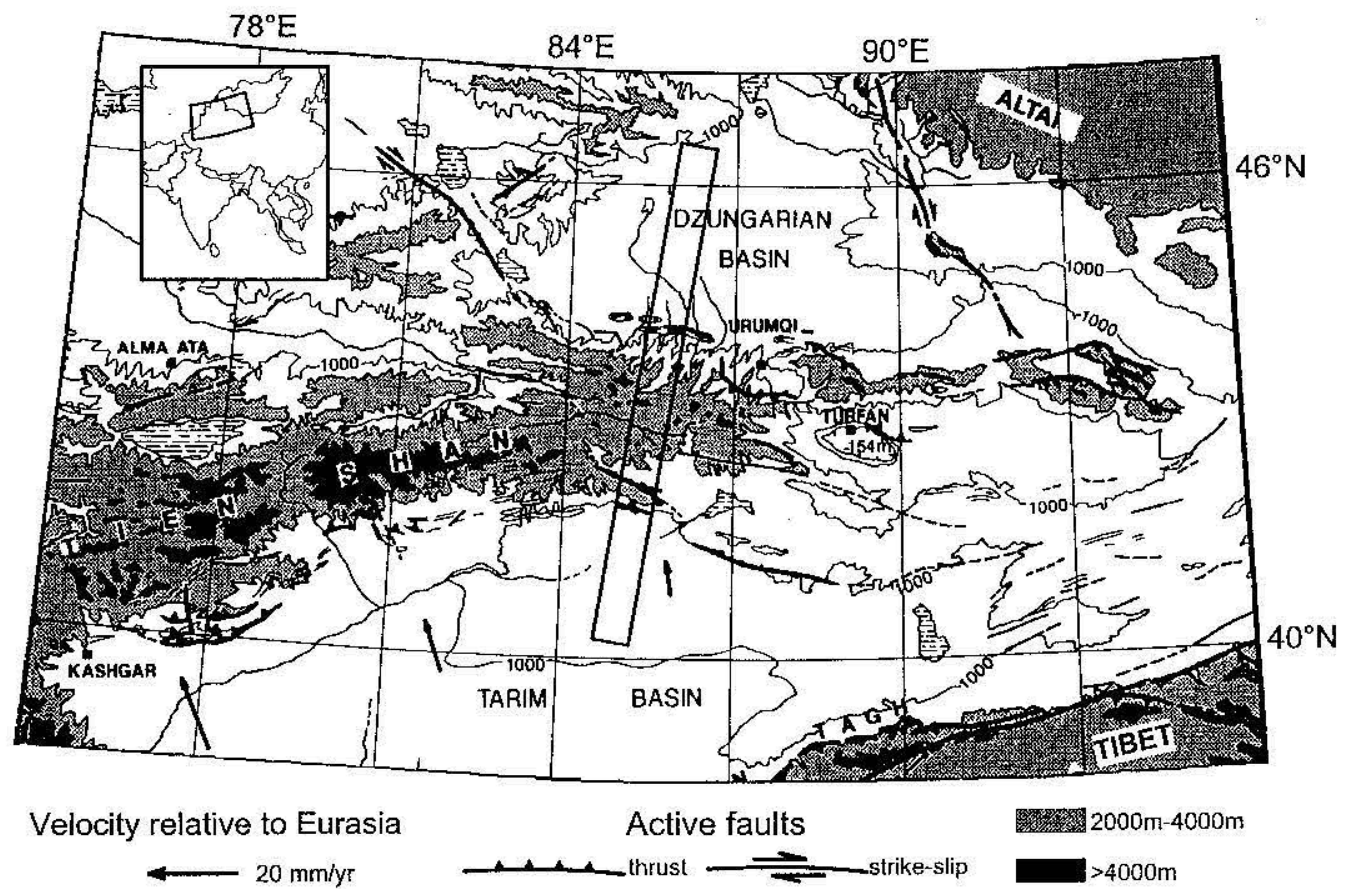

Figure 1a. Topography and seismotectonic setting of Tien Shan range.

form. The growth and maintenance of an intracontinental mountain range over long periods of time must therefore involve dynamical processes allowing for long-term localization of lithospheric strain below the mountain. Several mechanisms have been advocated. Intrinsic strain-softening properties of rocks could sustain localized thrust faulting at the crustal scalc. Alternatively, a range could result from shear stresses at base of the crust induced by lithospheric underthrusting or by some mantle dynamics [e.g., Beaumont et al., 1994; Ellis et al., 1995]. Such a mechanism may be suggested for mountains associated with subduction zones or with hotspots [Vogt, 1991] but seems inappropriate to explain most intracontinental mountains. In the case of the Tien Shan, a particular mantle dynamics has

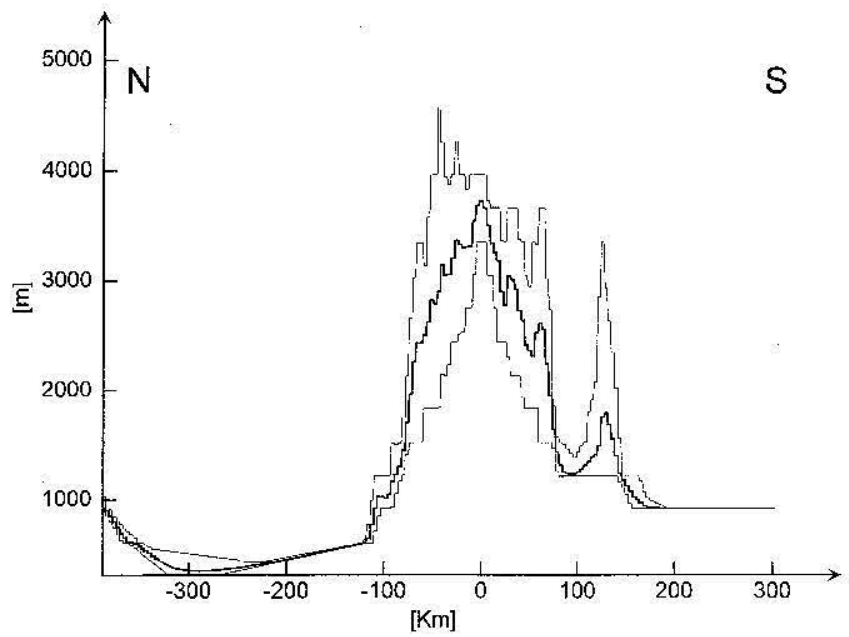

Figure 1b. Topographic cross section. Thick line is averagc elevation along the $50-\mathrm{km}$-wide, 650-km-long swath (box in Figure 1a). Thin lines indicatc minimum and maximum elevations, respectively. The difference of elevations between range and lowland is of the order of $3000 \mathrm{~m}$. been infcrred from gravity modeling [Burov et al., 1990] and seismic anisotropy [Makeyeva, 1992; Roecker et al., 1993], but we contend that it might not be the key factor. Our point is that coupling between surface processes and flow in the lower crust could provide an alternative and general explanation.

In this paper we first show that surface and tectonic processes are not independent processes and that they can interact. We suggest in particular that advection of material at the Earth's surface and horizontal flow in the crust might be coupled and that this coupling could permit mountain growth in response to horizontal shortening. This mechanism is then validated and investigated on the basis of numerical experiments in which the evolution of an already mature mountain range is modeled. The model accounts for the rheological layering of the lithosphere and for surface processes. We find that depending of the crosion rate compared to horizontal shortening, flow in the lower crust can be "outward" (from under the high topography) or "inward" (toward the crustal root of a high topography). When inward flow occurs, a mountain range can grow and no other mechanism is required to explain localized uplift. Some implications about the role of climatc on continental tectonics and on the geomorphology of mountain ranges are then derived.

\section{Interplays Between Surface and Tectonic Processes}

\section{Tectonic Forcing on Surface Processes}

Topographic contrasts are required to set up crosion and sedimentation processes. Tectonics is therefore a forcing factor of surface processes. Following Ahnert [1970] and Pinet and Souriau [1988], Summerfield and Hulton [1994] have recently compiled rates of denudation at the scale of major river basins. These studies indicate that denudation is primarily influenced by basin topography so that rates of denudation appear to be systematically high in areas of active tectonic uplift. Common 
values of mean denudation rates in such areas would bc of the order of a few $0.1 \mathrm{~mm} / \mathrm{yr}$ to about $1 \mathrm{~mm} / \mathrm{yr}$ at the scale of large drainage basins. Such rates are generally consistent with estimates derived from balancing sediment volumes over geological periods of time [Leeder, 1991; Summerfield and Hulton, 1994]. Thermochronologic studies indicate, however, local values as great as $1 \mathrm{~mm} / \mathrm{yr}$ (see Leeder [1991] and Molnar and England [1990] for critical reviews). The discrepancy between local and basin averaged estimates is due to the fact that tectonic uplift is probably distributed in bricf pulses over localized domains within a drainage basin [Copeland and Harrison, 1990]. In the absence of any tectonic feedback, common values of denudation rates should lead to the disappearance of a major mountain beit like the Tien Shan in a few million years. Pinet and Souriau [1988] demonstrated that denudation leads to an exponential decay of the topography of a range with a characteristic time constant of the order of 2.5 m.y.

\section{Coupling Between Denudation and Tectonic Uplift Due to Isostasy}

Isostasy provides an immediate mechanism that should link subsurface and surface processes. Redistribution of surface loads by erosion and sedimentation must induce tectonic deformation to maintain isostatic balance. Vertical uplift is expected to partly compensate unloading in the area subjected to denudation, while subsidence should occur in response to loading by sedimentation. This feedback mechanism may lead to some coupling between denudation and tectonic uplift [e.g., Ahnert, 1970]. A first consequence is that the time needed to crode a topographic relief must take into account removal of the topographic relief and of the crustal root. If local isostasy is assumed and if horizontal strains are neglected, denudation is dynamically compensated by uplift, and the charactcristic time of decay of the topography would then be of the order of 10 m.y. [Leeder, 1991]. It has becn argued that some kind of positive feedback may then arise [Molnar and England, 1990; Masek et al., 1994]. If the slopes of valleys steepen during river incision, isostatic readjustment following denudation in a mountain range may result in a net uplift of the higher summits in spite of the average lowering of reliefs. Erosion might thus induce some uplift of topographic summits, leading in turn to enhanced erosion. A rapid uplift of the Himalayan belt during the last few million years may have resulted from this process [Burbank, 1992]. Note, however, that while the peaks might reach higher elevations following isostatic adjustment, the net effect of erosion in that mode is crustal thinning. Thus this effect does not seem to be a fundamental ingredient in mountain-building processes.

\section{Coupling Between Surface Processes and Horizontal Strains}

As mentioned in the introduction, small lateral variations of the crustal thickness should drive horizontal flow in the lower crust. Some studies have already pointed out the importance of such a process in continental tectonics [c.g., Lobkovsky, 1988; Lobkovsky and Kerchman, 1991]. For example, Kruse et al. [1991] have shown that horizontal flow in the lower crust has regulated isostatic equilibrium during extension in the Basin and Range. The lower crust would have been extruded from under the high topography during that process. Following Westaway [1994], this sense of flow is called "outward." On the other hand, Gregory and Chase [1994] inferred "inward" flow, toward the crustal root, during the Laramide orogeny of the Frontal Range, Colorado. The characteristic time associated with flow in the lower crust, induced by the topography of a range of a few thousand meters high a few hundred kilometers wide, is of the order of a few million years. The characteristic times of erosional decay of the topography of a range and of lateral collapse of a crustal root are thus of the same order of magnitude. Since both processes are driven by topographic slopes, some coupling may arise. Although it is not often pointed out, it has long been recognized that this kind of process might play a major role in elevation changes within continents (see Westaway [1994] for an review of historical development of these ideas). Westaway [1994] made a case for such a coupling, with inward flow, in the context of extensional tectonics in western Turkey. He proposed that sediment loading in the sedimentary basins would have driven flow toward the uplifted area. This kind of process was first modeled by King and Ellis [1990], who modeled crustal extension using a thin clastic plate (upper crust) ovcriying an inviscid fluid (lower crust).

We propose that this kind of coupling might also appear in a compressional context. Let us consider a portion of a lithosphere, loaded with some initial range in regional isostatic balance and submitted to horizontal compression (Figure 2a). Because a thicker crust and bending stresses tend to reduce the strength of the lithosphere [Burov and Diament, 1995; Ranalli, 1994], the lithosphere is weaker bencath the range. At the same time, the stresses resulting from the slopes of the topography and of the Moho should drive horizontal flow in the lower crust beneath the high topography. In the absence of horizontal shortening and erosion the lower crust below the range would be extruded laterally, as discussed by Bird [1991] (Figure 2a). Our point is that if erosion takes place, a regime may be established in which horizontal shortening could be preferentially accommodated by crustal thickening in the area below the range (Figurc $2 b$ ). Surface processes remove matcrial from the range and feed the adjacent flexural basins, inducing isostatic imbalance. This imbalance produces in turn a temporary excess of normal stress below the foreland basins and a deficit below the range, favoring flow in the lower crust toward the crustal root. Ultimatcly, this coupled regime might lead to some dynamic equilibrium in which the amount of material removed by erosion would balance the material supplied to the range by subsurfacc deformation.

\section{Modeling: Principles and Numerical Implementation}

We developed a model in order to validate the coupled regime described in the previous section. For this purpose the model has to account for (1) surface processes, (2) the effect of topographic loads and of variations of crustal thickness on the mechanical behavior of the lithosphere, and (3) ductile flow in the crust. Therefore we have had to consider a depth and strain dependent rheology of the lithosphere. In this section we propose somc approximations and a numerical procedure to account for these basic properties. The resulting model allows computation of the deformation of a two-dimensional section of continental lithosphere subject to horizontal compression and to surface processes.

\section{Surface Processes}

We looked for a simple two-dimensional law that could simulate erosion and sedimentation at the scale of a mountain range. The evolution of a landscape results from the combina- 


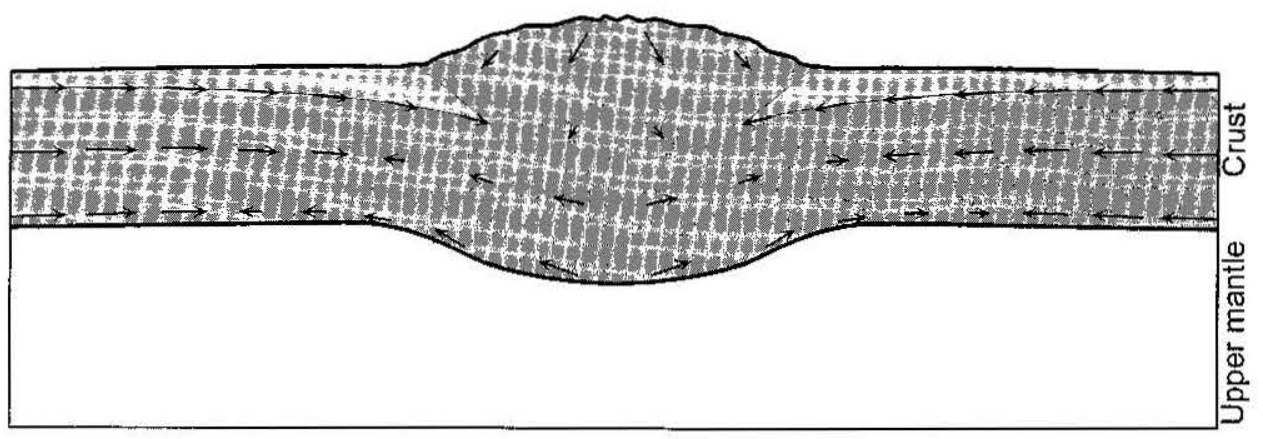

\section{b Erosion + Horizontal compression : Mountain Growth ?}

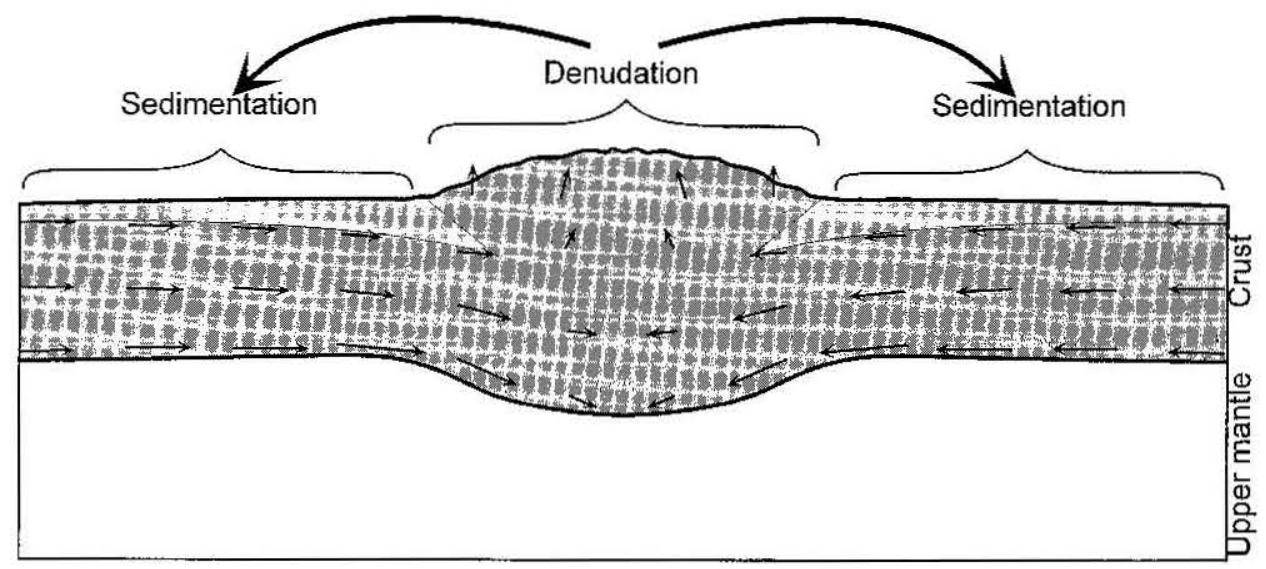

Figure 2. Velocity field in a deforming section of crust loaded with some range topography and submitted to horizontal shortening. We assume that the thick crust beneath the range is relatively weak and mechanically decoupled from the upper mantlc. (a) In the absence of surface processes the crustal root below the range is expected to spread out laterally ("outward" flow). (b) Denudation in highlands and sedimentation in lowlands may drive "inward" flow in the lower crust: denudation, which removes matcrial from steep and elevated topography, results in uplift due to isostatic rebound. Sedimentation, which transports eroded material to the lowlands, produces increased subsidence due to the increased load. Unloading beneath the range and loading beneath the piedmonts may thus force the lower crust to flow toward the mountain root. As a result, topographic uplift may be localized below the range, and the range can grow rather than spread laterally.

tion of weathering processes that prepare solid rock for erosion, and transportation by hillslope and stream processes (see Carson and Kirkby [1972] for a review). Although many factors, depending on the lithologies and on climate [e.g., Fournier, 1960], may control this evolution, quite simple mathematical models describing the geometrical evolution of the morphology at the small scale have been proposed and tested successfully [e.g., Chorley et al., 1984; Kirkby, 1986]. For example, the two-dimensional (2-D) evolution of a scarplike landform can be modeled assuming that the ratc of downslope transport of debris, $q_{c}$, is proportional to the local slope [Culling, 1960; Hanks et al., 1984; Avouac, 1993]:

$$
q_{e}=-k \frac{\partial h}{\partial x},
$$

where $k$ is the mass diffusivity coefficient, expressed in units of area per time (e.g., $\left.\mathrm{m}^{2} / \mathrm{yr}\right)$. In the assumption of mass conservation along a 2 -D section and no tectonic deformation, $h$ must obey

$$
\frac{\partial h}{\partial t}=-\frac{\partial q_{e}}{\partial x} .
$$

With constant $k$, equations (1) and (2) lead to the linear diffusion equation

$$
\frac{\partial h}{\partial t}=k \frac{\partial^{2} h}{\partial x^{2}} .
$$

This model of surface processes holds only for particular conditions. The regolith must form more rapidly than it is removed by surface transport, and slopes must not exceed the frictional angle of the material. Even for scarps formed in loose alluvium some complications arise when high scarps are considered. Scarps with height typically in excess of about $10 \mathrm{~m}$ in arid climatic zones tend to have systematically sharper curvatures at crest than at base [e.g., Andrews and Bucknam, 1987]. At the larger scale, hillslope and stream processes interact and the sediment transport then depends nonlinearly on the slope and on other factors such as the slope gradient, the area 
drained above the point, and the distance from the water divide, so that the simple 2-D linear diffusion does not apply in general [e.g., Gossman, 1976]. In spite of these limitations, we have chosen to stick to a linear diffusion law to model erosion in the upland. This model does not accurately mimic the spatial distribution of denudation in the mountain range, but it leads to a sediment yield at the mountain front that is roughly proportional to the mean clevation of the basin relative to that point (a rough approximation to the sediment yield resulting from a change of elevation $h$ over a horizontal distance $d$ is $k \times h / d)$ and therefore accounts for the apparent correlation between elevation and denudation rates observed by Ahnert [1970], Pinet and Souriau [1988], and Summerfield and Hulton [1994]. We did not apply the diffusion model to the whole system, however. We felt that we should take into account the major discontinuity in surface processes that occurs at the mountain front. As a river emerges into the adjacent basin, its gradient is sharply reduced and deposition occurs. The streams shift from side to side and build up alluvial fans that tend to form a broad gently sloping pediment at the base of the mountain range. In addition, a lateral drainage often develops along the foothills of mountain ranges (for example, the Gange along the Himalayas, the Parana along the Andes, or the Tarim along the Tien Shan). Altogether the formation of the pediment and lateral drainage tend to maintain gentle slopes in the foreland. There is therefore a sharp contrast between river incision that maintains a rugged topography with steep slopes in the mountain range and widespread deposition of alluvium in the foreland. This discontinuity of processes must be considered to model the sharp break in slope at the mountain front that is generally obscrved on topographic profiles across mountain belts (Figure 1b). In order to simulate this major change in surface processes, sedimentation in the lowland is modeled assuming "flat deposition": mass is conserved along the section and the sediment at the mountain front is distributed in order to maintain a flat horizontal topography in the foreland. We arbitrarily set the change from diffusional crosion to flat deposition at an clevation of $500 \mathrm{~m}$.

We considered values for $k$ varying between $10^{3}$ and $10^{4}$ $\mathrm{m}^{2} / \mathrm{yr}$ that yicld denudation rates of the order of a few tenths of a millimeter per year to $1 \mathrm{~mm} / \mathrm{yr}$ for a 200 - to $400-\mathrm{km}$-wide range with a few thousand meters of relicf.

In order to test the sensitivity of our model on the assumed crosion law we also considered nonlinear erosion laws of the form

$$
\frac{\partial h}{\partial t}=k^{*}\left(x, h, \frac{\partial h}{\partial x}\right) \frac{\partial^{2} h}{\partial x^{2}},
$$

where

$$
k^{*}\left(x, h, \frac{\partial h}{\partial x}\right)=k(x)\left(\frac{\partial h}{\partial x}\right)^{n}
$$

[c.g., Gossman, 1976; Andrews and Bucknam, 1987]. We will refer to the cases with $n=1,2$ as first- and second-order diffusion, respectively. In these cases we did not introduce the change in regime at the mountain front since the nonlinear effects already tend to form relatively smooth pediments. It should be noted that (4) differs from that obtained assuming a nonlinear diffusion coefficient in (1). In that case conservation of mass would lead to an additional term $(\partial k \% / \partial x)(\partial h / \partial x)$ in (4).

\section{Structure and Rheology of the Lithosphere}

Previous investigations of the interplay between erosion and tectonics have generally been conducted assuming either local isostasy [Ahnert, 1970; Leeder, 1991] or thin plate behavior of the lithosphere [Beaumont, 1981; Flemings and Jordan, 1990; Beaumont et al., 1992; Masek et al., 1994]. Some authors have actually considered the possibility for ductile flow in the lower crust and treated the lower crust as an inviscid fluid overlaid by a thin elastic plate [King et al., 1988; King and Ellis, 1990]. The effects of surface loads and of the variations of crustal thickness on the mechanical bchavior of the lithospherc have been neglected. The coupled regime described in the previous section assumes that strain localization below a range results from weakening of the lithosphere due to crustal thickening and bending stresses. In order to account for this process we can treat the lithosphere neither as a one-layer elastic plate with vertically integrated properties overlying an inviscid asthenosphere nor as a thin viscous sheet [e.g., England and McKenzie, 1983; Vilotte et al., 1982]. We consider the lithological and mechanical rheological layering of the lithosphere (Figure 3). Three lithological layers are distinguished: the upper crust, the lower crust, and the mantle. Each layer has specific properties: density, mechanical, and thermal constants (see notation section). We assume no compositional changes due to deformation or cooling. The lithological boundary between the upper and lower crust lies at a fixed depth of $20 \mathrm{~km}$. The bottom of the mantle lithosphere is limited by the $1330^{\circ} \mathrm{C}$ isotherm at a depth of about $250 \mathrm{~km}$.

At small differential stresses the rocks behave elastically. In terms of principal components the relationship between the stress tensor $\sigma$ and the strain tensor $\varepsilon$ can be written

$$
\sigma_{j}=2 \mu_{e} \varepsilon_{j}+\lambda\left(\varepsilon_{1}+\varepsilon_{2}+\varepsilon_{3}\right) \quad(j=1,2,3) .
$$

The parameters $\lambda$ and $\mu_{e}$ are Lamé's constants related to Young's modulus $E$ and Poissons's ratio $\nu$ as

$$
\begin{gathered}
\lambda=E \frac{\nu}{(1+\nu)(1-2 \nu)} \\
\mu_{c}=\frac{E}{2(1+\nu)} .
\end{gathered}
$$

Strain weakening by brittle failure or ductile flow occurs when clastic stresses reach some threshold above which unrecoverable strain grows without increase of stress. The conditions of brittle failure are independent of rock type and temperature but are strongly controlled by pressure [Byerlee, 1978]:

$$
\begin{array}{ll}
\sigma_{3}=\left(\sigma_{1}-\sigma_{3}\right) / 3.9 & \sigma_{3}<120 \mathrm{MPa} \\
\sigma_{3}=\left(\sigma_{1}-\sigma_{3}\right) / 2.1-100 & \sigma_{3} \geq 120 \mathrm{MPa} .
\end{array}
$$

This law should be written in terms of effective stresses to account for the effect of pore pressure. In this study we do not consider fluids.

Ductile flow in the lithosphere essentially results from thermally activated dislocation creep [e.g., Kusznir, 1991]:

$$
\dot{\varepsilon}=A^{*} \operatorname{cxp}\left(-H^{*} / R T\right)\left(\sigma_{1}-\sigma_{3}\right)^{n} .
$$

The values of the parameters are given in Table 1 . The ratio of the stress to strain rate defines an cffective non-Newtonian viscosity:

$$
\mu_{\rho f f}=\left(\sigma_{1}-\sigma_{3}\right) / 2 \dot{\varepsilon}
$$



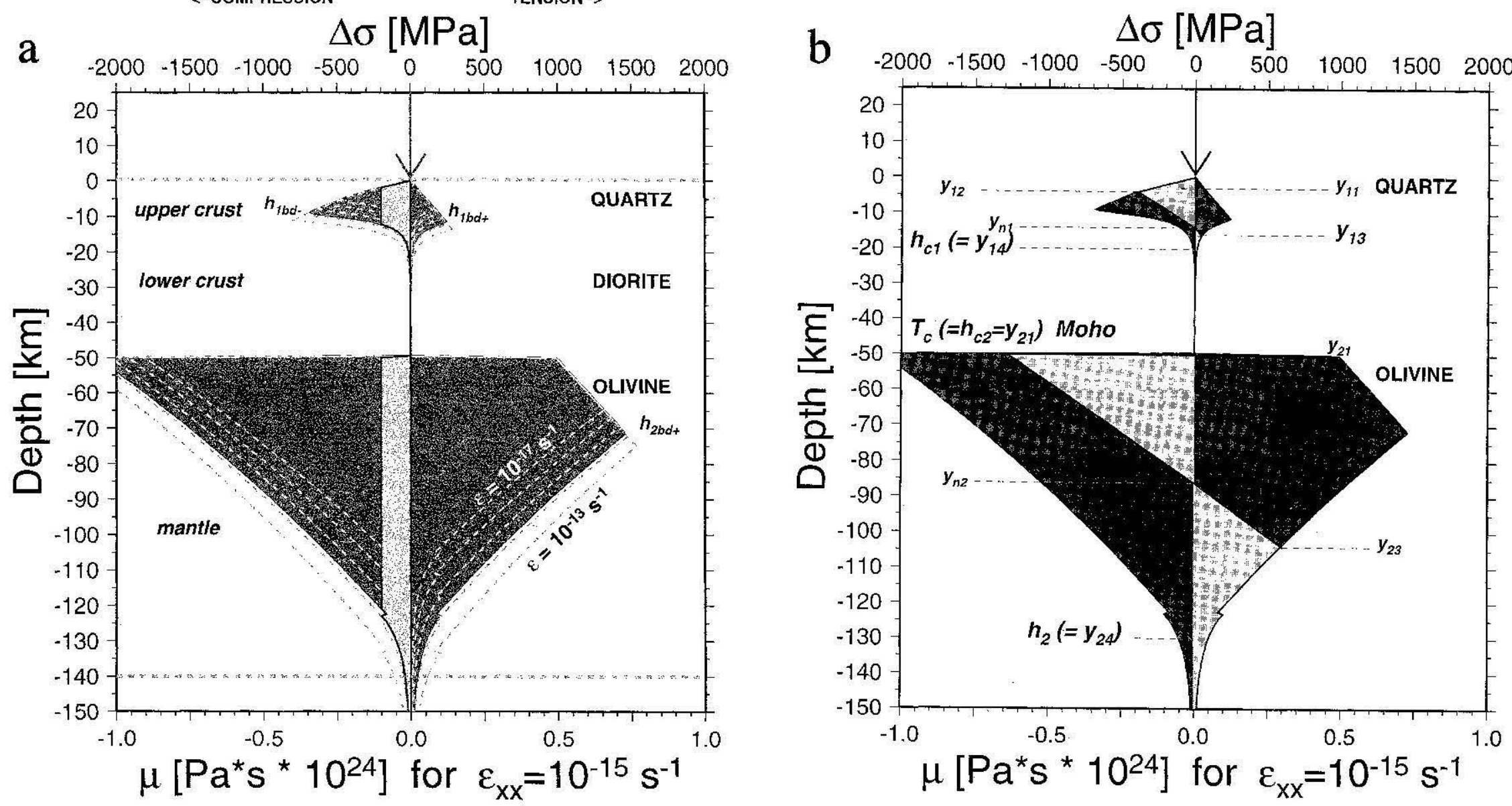

Figure 3. Yield strength envelope (equation (9)) of a $400 \mathrm{Ma}$ continental lithosphere with a 50 -km-thick crust, submitted to horizontal shortening with $\dot{\varepsilon}_{x .}=5 \times 10^{-15} \mathrm{~s}^{-1} . \Delta \sigma=\sigma_{1}-\sigma_{3}$ is the differential stress $\left(\sigma_{1}\right.$ and $\sigma_{3}$ are maximum and minimum principal stresses, respectively). As discussed in the text, the strength of the brittle domain is higher when the lithosphere is submitted to horizontal compression than when it is submitted to horizontal extension. In this example, the lower crust has a low temperature of creep activation and thus is mechanically decoupled from mantle. Dashed lines show ductile yield stress obtained for various strain rates between $10^{-17}$ and $10^{-13} \mathrm{~s}^{-1}$. The thick line in Figure $3 \mathrm{a}$ indicates the deviatoric stresses in the lithosphere when submitted to $1.5 \times 10^{13} \mathrm{~N}$ m horizontal compression. The parameters $h_{1 b d+}$ and $h_{1 b d-c o r r c s p o n d}$ to the depths of the brittle-ductile transition in the crust for tensional and compressive regimes, respectivcly; $h_{2 b d+}$ and $h_{2 b d-}$ correspond to those in the mantle. The depth distribution of deviatoric stresses is shown in Figure $3 b$ when an additional downward bending moment of $7 \times 10^{17} \mathrm{~N} \mathrm{~m} / \mathrm{m}$ is applied. The elastic cores in the crust and upper mantle are reduced due to flexure of lithosphere. Bending stresses lead to inelastic bchavior (flow and brittle failure) in large zones of mantle and crustal lithosphere (e.g., material flows below the point $y_{13}$ in crust and below the point $y_{23}$ in mantle). All other notations are defined in Appendix A. 
Tablc 1. Parameters of Dislocation Creep for Major Lithospheric Rocks and Minerals

\begin{tabular}{lccc}
\hline \multicolumn{1}{c}{ Mineral/Rock } & \multicolumn{1}{c}{$\begin{array}{c}A^{*}{ }^{-n} \mathrm{~s}^{-1} \\
\mathrm{~Pa}^{*}\end{array}$} & $\begin{array}{c}\mathrm{kJ}^{*}, \\
\text { mol }\end{array}$ & $n$ \\
\hline Quarzite (dry) & $5 \times 10^{-12}$ & 190 & 3 \\
Diorite (dry) & $5.01 \times 10^{-15}$ & 212 & 2.4 \\
Diabasc (dry) & $6.31 \times 10^{-20}$ & 276 & 3.05 \\
Olivine/dunite (dry) & $7 \times 10^{-14}$ & 520 & 3 \\
\hline
\end{tabular}

Sce equation (7). The data sources are Brace and Kohlsted [1980], Carter and Tsenn [1987], and Kirby and Kronenberg [1987].

"Dislocation climb at $\sigma_{1}-\sigma_{3} \leq 200 \mathrm{MPa}$. For olivine (Dorn's dislocation glide) at $\left.\sigma_{1}-\sigma_{3} \geq 200 \mathrm{MPa}\right), \dot{\varepsilon}=\dot{\varepsilon}_{01} \exp \left[-H^{*}(1-\right.$ $\left.\left.\left(\sigma_{1}-\sigma_{3}\right) / \sigma_{0}\right)^{2} / R T\right]$, where $\varepsilon_{0}=5.7 \times 10^{11} \mathrm{~s}^{\prime}, \sigma_{0}=8.5 \times 10^{3} \mathrm{MPa}$; $H^{*}=535 \mathrm{~kJ} \mathrm{~mol}^{-1}$.

Although ductile deformation occurs even under low differential strcsses, a ductile yield strength can be defined. If boundary conditions are given in terms of rate of displacement, a average strain rate can be derived. This "basic" strain rate is used to define a stress threshold from (7). Owing to the nonlinearity in (7), if the stress is slightly less than this level, ductile deformation will process very slowly so that most of the imposed deformation will be absorbed clastically. For example, for olivine the strain rate decreases by a factor of 1000 if the stress lies $10-15 \%$ below the "threshold" level. On the other hand, the stress level cannot significantly cxceed this threshold since it would require a strain rate much higher that the one that is imposed from boundary conditions. This threshold thus defines a ductile yicld strength. A temperature about $250^{\circ}-$ $300^{\circ} \mathrm{C}$ must be excceded for ductilc deformation of quartz, whereas for olivine it should be $600^{\circ}-700^{\circ} \mathrm{C}$ [e.g., Brace and Kohlstedt, 1980; Carter and Tsenn, 1987]. It results in the yicld stress envelope (YSE) being controlled by the conditions for brittle failure in the shallow crust and upper mantie and by the condition for ductile failure in the deep crust and deep upper mantle. Combining rheological laws (cquations (6) and (7)) thus define a piecewise continuous yield stress envelope (YSE) (Figure 3) defined as contours $\sigma^{f}=\sigma^{f}(x, y, l, \dot{\varepsilon})$ such that $\sigma^{f}=\operatorname{sign}(\varepsilon) \min \left\{\left|\sigma^{b}\lceil x, y, t, \dot{\varepsilon}, \operatorname{sign}(\varepsilon)]\right|,\left|\sigma^{d}(x, y, t, \dot{\varepsilon})\right|\right\}$

where $\sigma^{t}[x, y, t, \dot{\varepsilon}, \operatorname{sign}(\varepsilon)], \sigma^{d t}(x, y, t, \dot{\varepsilon})$ are the "brittle" and "ductile" yicld stresses from (6) and (7). Owing to asymmetry of the Byerlee's law (6), the yield stress depends on the mode of deformation: $\operatorname{sign}(\varepsilon)=1$ for horizontal compression and -1 for horizontal cxtension.

The differential stress $\sigma(x, y)$ at a point is taken to be equal to the minimum of $\sigma^{\prime \prime}$ and $\sigma^{f}$ computed as a function of the local strain $\varepsilon=\varepsilon(x, y, t, \dot{\varepsilon})$ :

$$
\sigma(\varepsilon)=\operatorname{sign}(\varepsilon) \min \left(\left|\sigma^{\prime}\right|,\left|\sigma^{\prime \prime}(\varepsilon)\right|\right)
$$

where $\sigma^{\prime \prime}(\varepsilon)$ is the elastic differential stress according $10(5)$. If $\sigma^{\prime \prime}$ exceeds $\sigma^{\prime}$, the material is considered as ductilc or brittlc, depending on which rhcology limits the yield strength. Equation (10) implies that the lithosphere remains clastic if imposed stress does not exceed the yicld stress.

This formulation accounts for the lithosphere getting weaker when submitted to increasing horizontal forces (Figure 3a) or flexural stresses (Figure 3b) and when the crust gets thicker. Most of the upper crust remains clastic (at depths between 5 and $15-20 \mathrm{~km}$ ). The crust is mostly ductile below $15-20 \mathrm{~km}$.
Depending on the gcotherm and strain rates, the first $30-70$ $\mathrm{km}$ of the mantle lithosphere remains elastic.

\section{Thermal Model}

A thermal model is required to define the rheology of the lithosphere and to fully account for the effect of crustal thickening on the rheology of the lithosphere. In this paper the geotherm is computed according to a half-space heat transfer model (for details, sce Burov et al. [1993] and Burov and Diament $[1995]$ ). Heat transfer equations are solved scparately for the upper crust, lower crust, and mantle:

$$
\dot{T}+u T_{x}^{\prime}+v l_{y}^{\prime}-\chi_{j} \Delta T=H_{d}+H_{r}+\tau \Omega,
$$

with conditions of temperature and heat flux continuity across the interfaces. The primes indicate differentiation with respect to the spatial coordinate; $\chi_{f}$ is the thermal diffusivity in the considered layer $\left(\chi_{c 1}, \chi_{c 2}, \chi_{m}\right.$ in notation section). The radiogenic heat $H_{r}$ is $\chi_{c 1} k_{c 1}^{-1} \rho_{c} H_{s} \exp \left(-y h_{r}^{-1}\right)$ in the upper crust. The heat production is $\mathrm{H}_{c 2} \mathrm{C}_{c: 2}^{-1}$ in the lower crust and zero in the mantle. The adiabatic temperature gradient in the asthenosphere, $\Omega$, is $0.3^{\circ} \mathrm{C} / \mathrm{km}$ [e.g., Turcotte and Schubert, 1982].

The boundary and initial conditions are $T\left(x, 0, t_{a}\right)=0^{\circ} \mathrm{C}$ (temperature at the upper surface is constant at time $t_{a}$, where $t_{a}$ is the thermal age); $T(x, a, t)=T_{m}=1350^{\circ} \mathrm{C}(a \cong 250$ $\mathrm{km}$ is the depth to the thermal bottom, or thermal thickness of the lithosphere [Burov et al., 1993]); $T(x, y, 0)=T_{m}$ (homogencous temperature distribution at the beginning). The parameter $t_{a}$ is defined as the age of the last thermal event determined from gcological data. In this study we used the geotherm that was obtained for the Tarim and Tien Shan area by Burov et al. [1993] that corresponds to a 50-km-thick crust with 400 m.y. age. Since we investigate the evolution of the system on a short time span (10)-30 m.y.) compared to the thermal age, we neglect the few percent perturbation to the gcotherm due to heat conduction. The thermal model also neglects the screening effect of sedimentation duc to the low conductivity of sediments [England and Richardson, 1977] as well as lateral heat advection and viscous heat dissipation. This model might appear oversimplificd, but it should be noticed that the simplifications tend to underestimate the temperature in the crust so that it should not particularly favor ductile flow in the lower crust.

\section{Numerical Implementation of the Model}

In this section we describe the numerical procedure used in the modeling. We distinguish between the competent and weak layers (Figure 4). The competent layers [e.g., Sinith, 1975; Burov and Diament, 1995] are those which are assumed to contribute significantly to the flexural strength of the lithosphere. It encompasses the domains that are clastic but also part of the inelastically deforming region. As a convention, a domain is competent if the yicld strength is greater than $5 \%$ of the lithostatic pressurc [Burov and Diament, 1995]. Only the competent layers are considered in the computation of the flexural response to the applied vertical and horizontal forces. The geometry and thickness of the mechanical layers depend on the lithological layering and on the stress field. Since both evolve during a numerical experiment, the mechanical structure is computed again on cach time step. Vertical deflections $(w)$ of the competent portions of the crust and mantle lithosphere due to change in the applied stress (in particular, in 


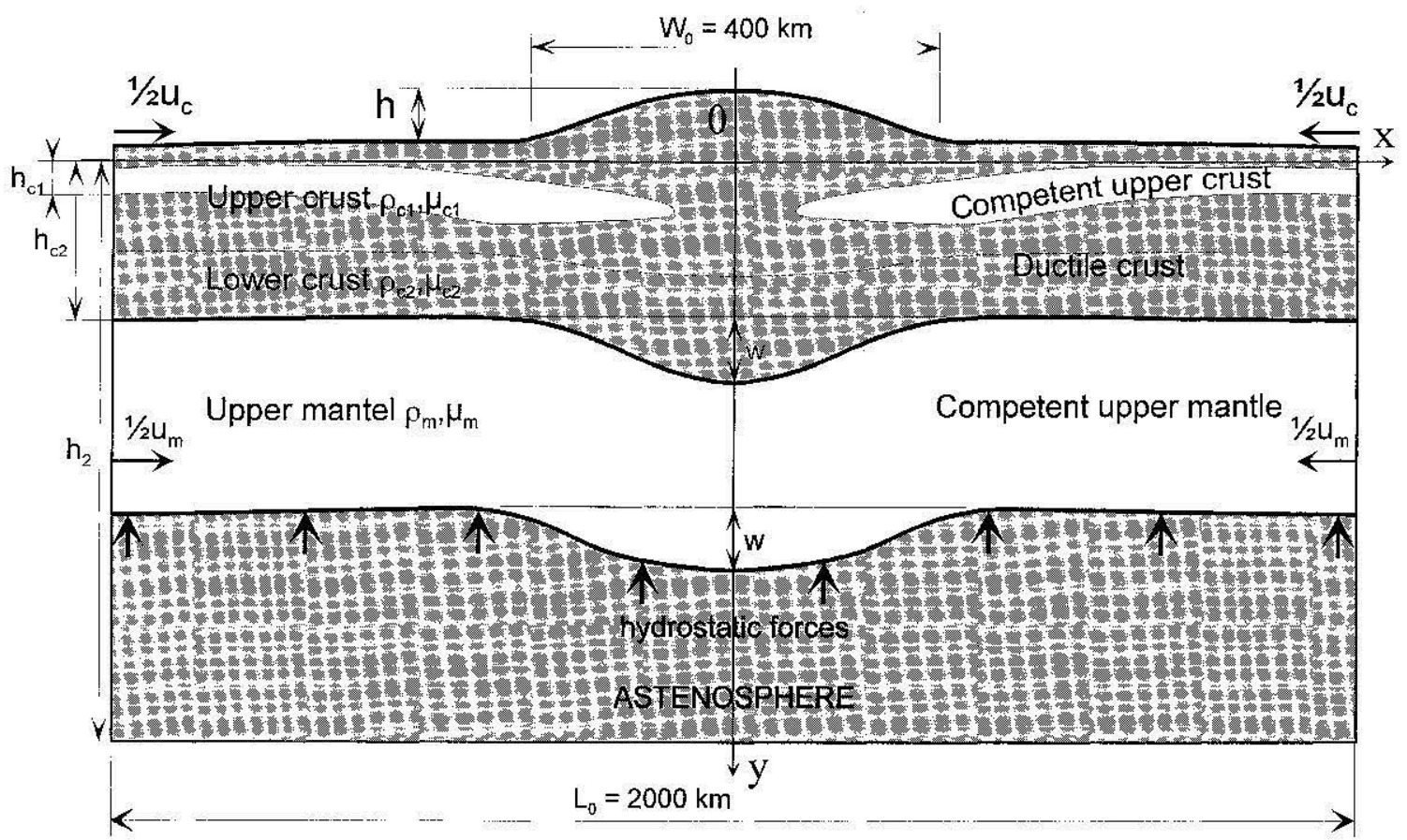

Figure 4. Initial geometry and boundary conditions. Initial range is a Gaussian mount of $\sim 400 \mathrm{~km}$ width and $3 \mathrm{~km}$ height placed on a Paleozoic lithospherc with initially $35-\mathrm{km}$-thick crust. The total width of the region is $2000 \mathrm{~km}$. The $2000-\mathrm{km}$-long section is submitted to horizontal shortening $u$, corresponding to the average strain rate $\dot{\varepsilon}_{x, x}=u / L$. Hydrostalic (Winkler) forces are assumed at the bottom of the lithosphere.

response to variation of the thickness of the viscous channel in the lower crust, erosion, and sedimentation at the surface) are treated as instantaneous deflections of flexible layers (Appendix A). Flow in the ductile crust is driven by the deflection of the competent layers that bound the low-viscosity channel. The normal load which is the weight of the topography $p,(x)$ and of the upper crustal layer (thickness $h_{c 1}$ and density $\rho_{c 1}$ ) is applied to the surface of the lower crustal layer through the llexible competent upper crustal layer. Deformation in the lower crust is modeled as flow of a non-Newtonian fluid in a channel with variable thickness. No horizontal flow at the axis of symmetry of the range $(x=0)$ is allowed. Away from the mountain range, where the channel has a nearly constant thickness, the flow is computed according to the thin channel approximation (Appendix B). Since the conditions for this approximation are not completely satisfied in the thickened region, we use a semianalytical solution for the ascending flow fed by remote channel source (Appendix C). The distance $a_{l}$ at which the channel flow approximation is replaced by a formulation for the ascending flow, is equal to one to two thicknesses of the channel, depending on the integrated strength of the upper crust (Appendixes B and C). We impose continuity of the integrated flux at the boundary between the two modcls.

Since the brittle-clasto-ductile (BED) rheology implies decoupling between the mantle and crust, in particular where the crust is thick, deformation of the crust is expected to be relatively insensitive to what happens in the mantle. Shortening of the mantle lithosphere is therefore neglected.

The uppermost crust deforms brittlely (Figure 3). The flow could be approximated by a viscous flow assuming some depthaveraged viscosity defined as $\bar{\mu}_{\mathrm{cff}}=\bar{\sigma}^{\prime l} / 2 \dot{\varepsilon}$ [Beekman, 1994]. We could also extend the solution of the equations for the horizontal flow to the stronger upper portions of the upper crust. However, owing to both higher viscosity and much lower thickness of the strong upper crustal layers, we simply assume that $v=v\left(y_{13}\right)$ and $u=u\left(y_{13}\right)$ for $y \leq y_{13}(y$ is positive downward).

The various equations that define the mechanical structure of the lithosphere (equations (5)-(7) and (9)-(11)), flexure of the competent layers (equation (A1)), ductile flow in the ductile crust (equations (B5), (B6), and (C3)), erosion (equation (3) or (4)), and sedimentation at the surface (equation (12e)) are solved according to the following scheme:

$$
u_{k-1}, v_{k-1}, T_{i(k-1)}, w_{k-1}, h_{k-1}+\mathrm{BC} \& \mathrm{IC}_{k} \rightarrow(11) \rightarrow T
$$

$$
\begin{aligned}
& T, \dot{\varepsilon}, A, H^{*}, n, T_{c(k-1)} \rightarrow((5)-(7),(9)-(10)) \\
& \rightarrow \sigma^{f}, h_{c: 1}, h_{c 2}, h_{m} \\
& \sigma^{f}, h_{c: 1}, h_{c: 2}, h_{m}, h_{k-1}, p_{k-1}^{-}, p_{k-1}+\mathrm{BC}_{k} \\
& \rightarrow(\mathrm{A} 1) \rightarrow w_{k}, T_{c(k)}, \sigma(\varepsilon), y_{i j k t} \\
& w_{k}, \sigma(\varepsilon), y_{i k, k}, \tilde{h}_{k-1}, \sigma^{f}, \dot{\varepsilon}, h_{k-1}, T_{c k}+\mathrm{BC}_{k} \\
& \rightarrow((\mathrm{B} .5),(\mathrm{B} .6),(\mathrm{C} .3)) \rightarrow u_{k}, v_{k}, \tilde{h}_{k}, h_{k}, T_{c k+1}, \tau_{x y} \\
& h_{k}\left(\text { i.c., } \mathrm{IC}_{k}\right) \rightarrow(3-4) \rightarrow h_{k: 1}
\end{aligned}
$$

where left-hand sides are input and right-hand sides are output and $\mathrm{BC}$ and IC refer to boundary and initial conditions, respectively. Notation $(k)$ implies that related value is used on $k$ th numerical step. Notation $(k-1)$ implies that the value is taken as a predictor from the previous time step. Notation $(k+1)$ means that the corrected value will be used in the next step. All variables are defined in the notation section. 
The following continuity conditions are satisfied at the interfaces between the competent layers and the ductile crustal channel:

Continuity of vertical velocity

$$
v_{c 1}^{-}=v_{c 2}^{+} ; v_{c 2}^{-}=v_{m}^{-}
$$

Continuity of normal stress

$$
\sigma_{s y_{c 1}}^{-}=\sigma_{y y_{c 2}}^{+} ; \quad \sigma_{y_{y_{c 2}}}^{-}=\sigma_{y y_{m}}^{-}
$$

Continuity of horizontal velocity

$$
u_{c 1}=u_{i 2}^{\prime} ; \quad u_{c 2}^{-}=u_{m}^{+}
$$

Continuity of the tangential stress

$$
\sigma_{x y_{1} 1}^{-}=\sigma_{x y_{c 2} ;}^{\prime} ; \quad \sigma_{x y_{c 2}}^{*}=\sigma_{x y_{m}}^{+}
$$

Kinematic condition

$$
\partial \tilde{h} / \partial t=v_{c 2}^{+} ; \quad \partial w / \partial t=v_{c 2}^{-}
$$

Superscript plus and minus refer to the values on the upper and lower interfaces of the corresponding layers, respectively. The subscripts $c_{1}, c_{2}$, and $m$ refer to the strong crust ("upper"), ductile crust ("lower"), and mantle lithosphere, respectively. Power law rheology results in self-lubrication and concentration of the flow in the narrow zones of highest temperature, that is, near the Moho. Therefore there is little difference between assuming no-slip or free slip for the ductile crust.

The spatial steps used in calculations are $d x=2 \mathrm{~km}, d y=$ $0.5 \mathrm{~km}$. The requirement of stability of integration of the diffusion equations (3), (4) $\left(d t<0.5 d x^{2} / k\right)$ implies a maximum time step of 2000 years for $k=10^{3} \mathrm{~m}^{2} / \mathrm{yr}$ and of 20 years for $k=10^{5} \mathrm{~m}^{2} / \mathrm{yr}$. It is less than the relaxation time for the lowest viscosity value $\left(\sim 50\right.$ years for $\left.\mu=10^{19} \mathrm{~Pa} \mathrm{~s}\right)$. We chose a time step of 20 years in all computations.

\section{Experiments and Results}

\section{Description of Experiments}

We conducted scries of experiments in which a 2-D section of a continental lithosphere, loaded with some initial range, is submitted to horizontal shortening (Figure 4). The shortening rate in the crust is assumed equal to that in the mantle ( $u_{c}=$ $u_{m}$ ). Our goal was to validate the coupled regime described in the first section and to check whether it can allow mountain growth. Our purpose was not to explain how some small initial irregularity of the topography might develop into a mountain belt. This question is beyond the scope of this study because fault initiation and propagation were not considered. We only address the problem of the growth and maintenance of a mountain range once it has reached some mature geometry.

We thus consider a 2000 - $\mathrm{km}$-long portion of lithosphere loaded by an initial major topographic irregularity. We chose a 300- to 400-km-wide "Gaussian" mountain (a Gaussian curve with variance $\sigma=100 \mathrm{~km}$ ). The range has a maximum elevation of $3000 \mathrm{~m}$ and is initially regionally compensated. The initial geometry of the Moho was computed according to the flexural response of the competent cores of the crust and upper mantle and neglecting viscous flow in the lower crust [Burov et al., 1990]. In this computation the possibility of internal deformation of the mountain range or of its crustal root is neglected. The section is then submitted to horizontal shortening at rates

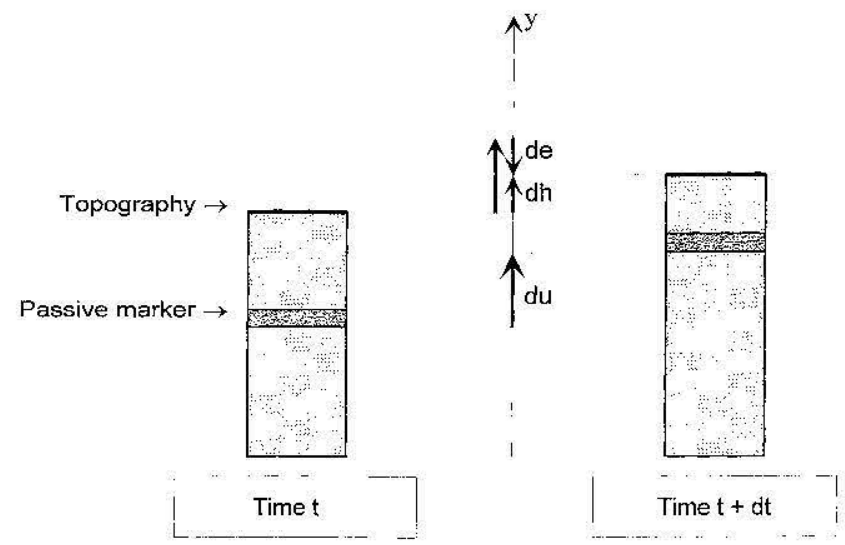

Figure 5. Definitions of tectonic uplift (subsidence if $<0$ ), $d u$; topographic uplift (subsidence if $<0$ ), $d h$; and denudation (sedimentation if $<0$ ), de. By definition, $d u=d h+d e$.

from about $1 \mathrm{~mm} / \mathrm{yr}$ to a few centimeters per year. These rates largely span the range of most natural large-scalc examples of active intracontinental mountain range. Each experiment is conducted over about 15-20 m.y. with internal time step of 20 years. The geometries of the different interfaces (topography, upper crust-lower crust, Moho, basement-sediment in the foreland) are computed for each time step. We also determine the rate of uplift of the topography, $d h / d t$; the rate of tectonic uplifi or subsidence, $d u / d t$; the rate of denudation or scdimentation, de/dt (Figure 5), as well as stress, strain, and velocity fields in the lithosphere. The relief of the range, $\Delta h$, is defined as the difference between the elevation at the crest $h(0)$ and in the lowlands at $500 \mathrm{~km}$ from the range axis, $h(500)$.

In the case where there are no initial topographic or rheological irregularities, the medium has homogeneous properties and therefore thickens homogeneously. There are no horizontal or vertical gradients of strain so that no mountain can form. If the medium is initially loaded with a mountain range, the flexural stresses (300-700 MPa, Figure 6a) can be 3-7 times higher than the excess pressure associated with the weight of the range itself $(\sim 100 \mathrm{MPa})$. The deviatoric stresses may be higher than the lithostatic pressure up to depths of $15-20 \mathrm{~km}$ and remain comparable with the pressure up to depths of order $100 \mathrm{~km}$ (depending on the rheology). As a result the competent cores are thinnest in the area below the range (Figure 6b). Horizontal shortening of the lithosphere tends therefore to be absorbed preferentially by strain localized in the weak zone beneath the range. In all experiments the system evolves rapidly during the first $1-2$ m.y. because the initial geometry is out of dynamic equilibrium. After this reorganization some kind of dynamic equilibrium settles in which the viscous forces due to flow in the lower crust also participate to the support of the load.

\section{Case 1, No Surface Processes: "Subsurface Collapse"}

In the absence of surface processes the lower crust is extruded from under the high topography (Figure 7). The crustal root and the topography spread out laterally (Figure 8a). Horizontal shortening leads to a general thickening of the medium, but the tectonic uplift below the range is smaller than below the lowlands so that the relief of the range, $\Delta h$, decays with time (Figure $8 b$ ). The system thus evolves toward a regime of 

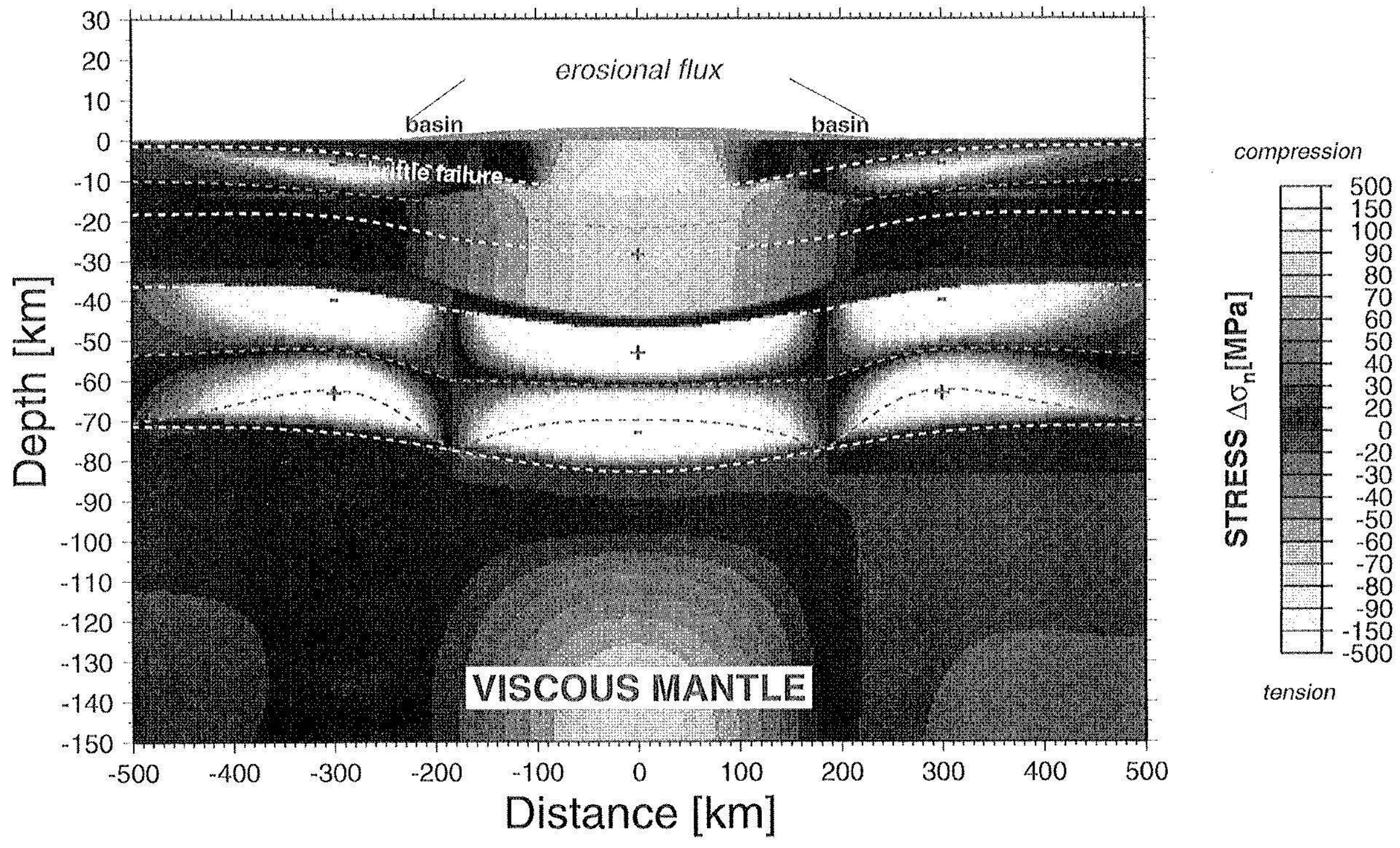

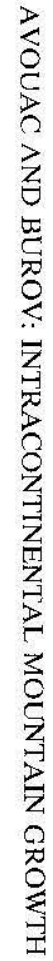

Figure 6a. Differential stresses in the lithosphere for a particular experiment $\left(k=7500 \mathrm{~m}^{2} / \mathrm{yr}, \dot{\varepsilon}_{x x}=0.7 \times 10^{-15} \mathrm{~s}^{-1}, u=\right.$ $4.4 \mathrm{~cm} / \mathrm{yr}, t=5 \mathrm{~m} . \mathrm{y}$.). Note flexural stresses and the concentration of stress in the lower crust beneath the range. Pluses and minuses refer to domains in compression and tension, respectively. 


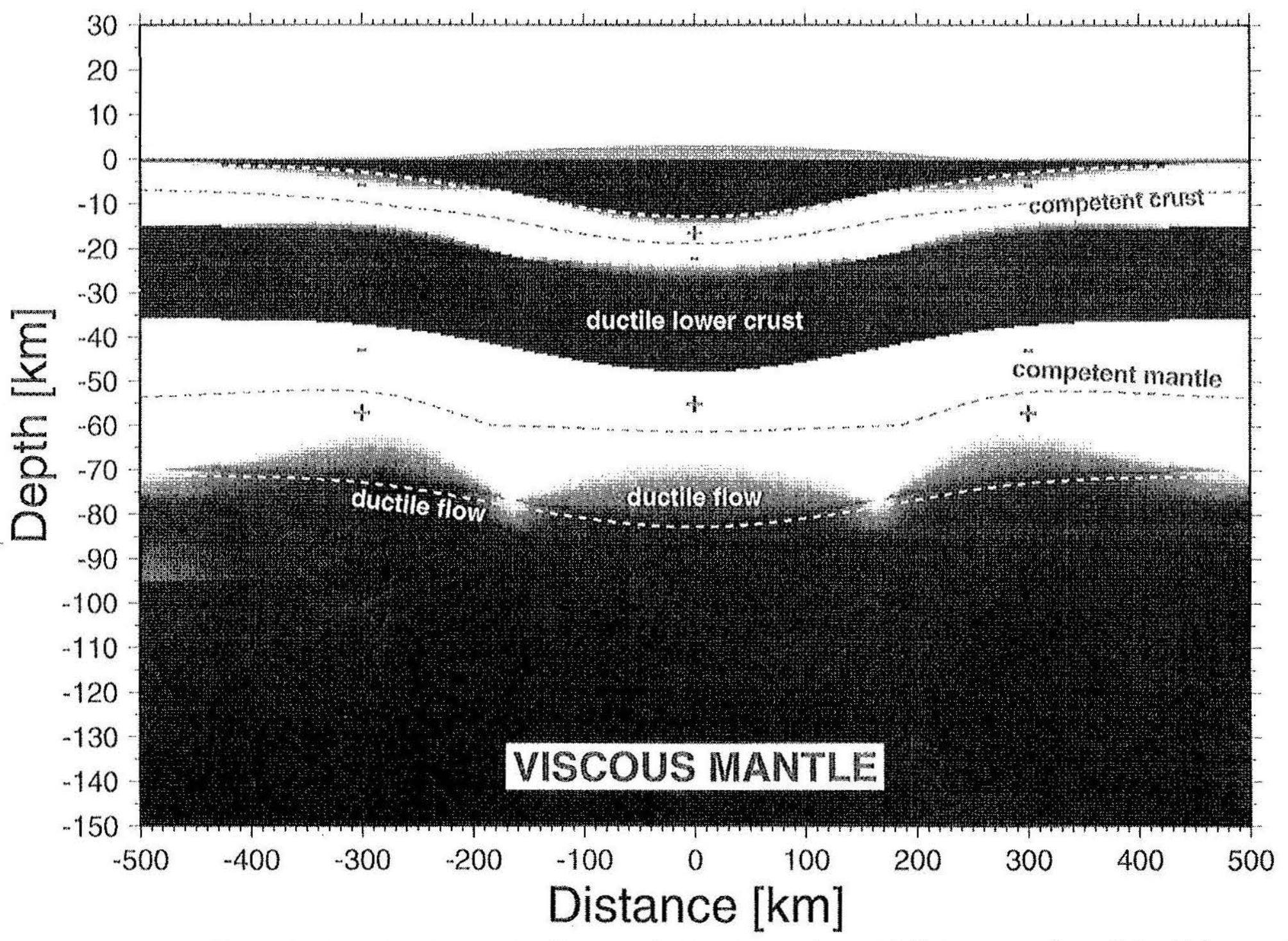

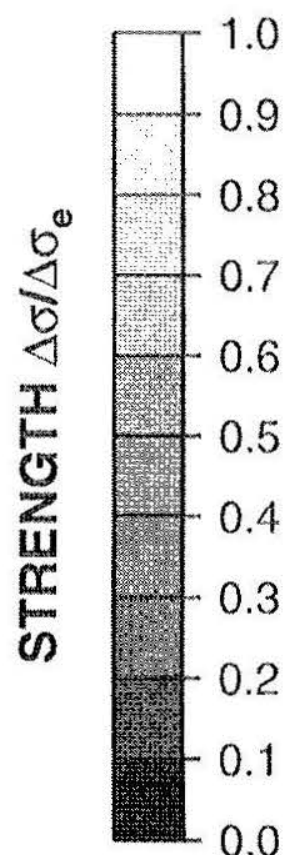

Figure 6h. Strength variations in the lithosphere for the same experiment as in Figure 6a. In order to distinguish between the competent and weak domains, the stresses are compared to the elastic stress $\Delta \sigma_{e}$ that would be expected for the same strain. White areas $\left(\Delta \sigma / \Delta \sigma_{e}>0.9\right)$ correspond to elastic "cores." The dark areas represent weak domains where the YSE has been reached (in the brittle or ductile regime). Note that the elastic cores are significantly reduced beneath the range, where local isostasy can be approached. The effect of weakening of the lithosphere by surface load favors localization of deformation in the vicinity of the range. 


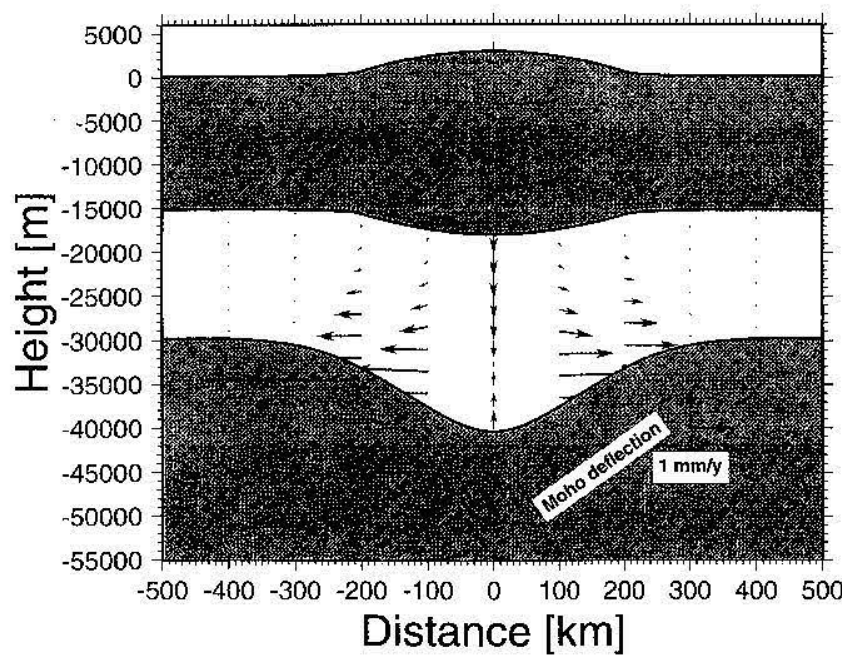

Figure 7. Outward flow pattern in the lower crust in the case of no erosion. The crustal root below the range is extruded laterally driven by the shear stresses due to the slopes of the topography and of the Moho. Velocity $u_{x}$ at $y=y_{13}$ associated with overall compression is subtracted. In this experiment, the $2000-\mathrm{km}$ long section is submitted to $6.3 \mathrm{~mm} / \mathrm{yr}$ horizontal shortening.
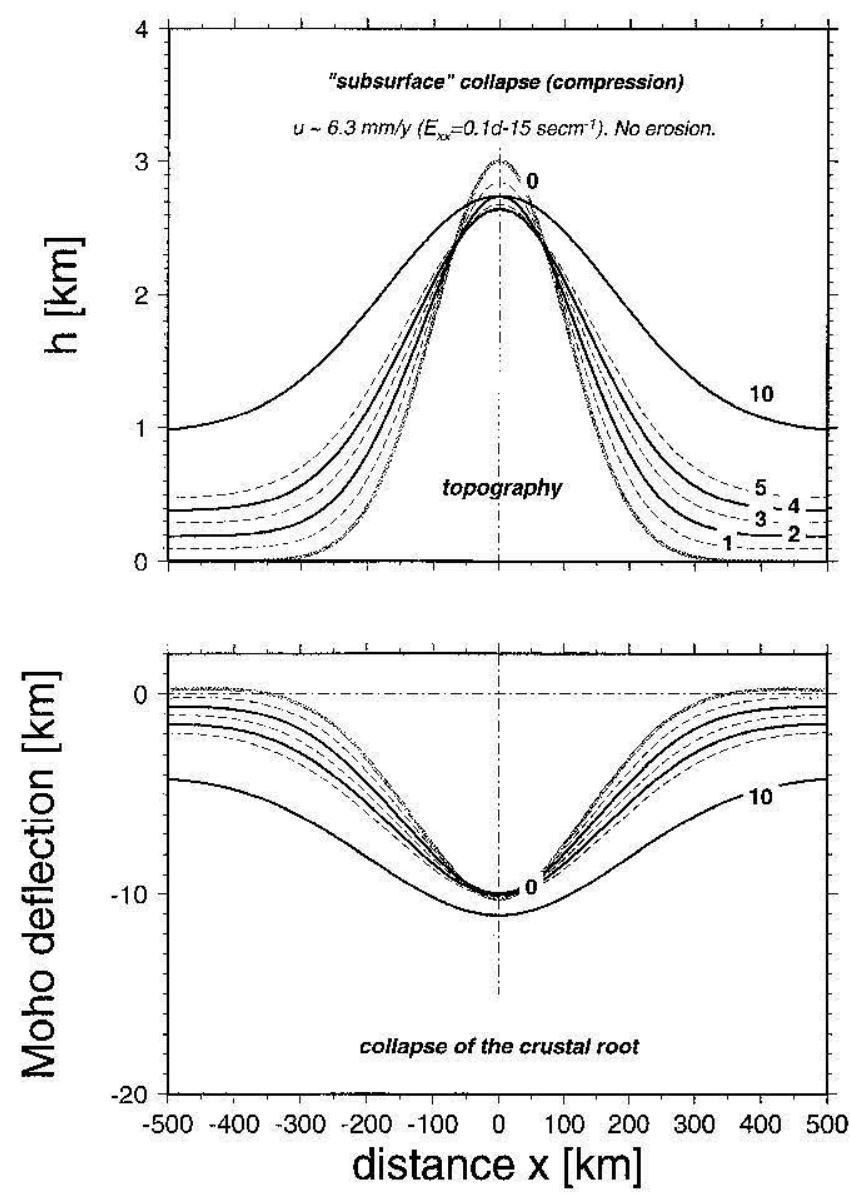

Figure 8a. A case example of "subsurface collapse" when no erosion is applied. Elevation at crest of the range decays as a result of the subsurface deformation as shown in Figure 7 . The $2000-\mathrm{km}$-long section is submitted to $6.3 \mathrm{~mm} / \mathrm{yr}$ horizontal shortening. Evolution (top) of topography and (bottom) of Moho from 0 to $10 \mathrm{~m} . \mathrm{y}$. The different curves are labeled according to time $(0,1,2,3,4,5,10$ m.y.). homogeneous deformation with a uniformly thick crust. In the particular case of a $400-\mathrm{km}$-wide and $3-\mathrm{km}$-high range it takes about $15 \mathrm{~m}$.y. for the topography to be reduced by a factor of 2. If the medium is submitted to horizontal shortening, the decay of the topography is even more rapid due to strain weakening. These experiments actually show that assuming a standard rheology for the crust, no intrinsic strain softening properties of the material, and no particular mantle dynamics, a range should collapse in the long term, as a rcsult of subsurface deformation, even with horizontal shortening of the lithosphere. This regime in which a range decays by lateral extrusion of the lower crustal root might be called "subsurface collapse."

\section{Case 2, No Shortening: "Erosional Collapse"}

If erosion is relatively active ( $k$ of the order of $10^{4} \mathrm{~m}^{2} / \mathrm{yr}$ ), the topography of the range is washed out rapidly (Figure 9a). Isostatic readjustment compensates for only a fraction of the denudation, and the elevation in the lowland increases as a result of crustal thickening essentially due to sedimentation (Figure 9b). Although mechanical collapse of the crustal root also participates in the process of decay of the range, we may call this regime "erosional collapse." The time constant associated with the decay of the relief in this regime depends on the mass diffusivity (Figure 9c). For $k=10^{4} \mathrm{~m}^{2} / \mathrm{yr}$, denudation rates are of the order of $1 \mathrm{~mm} / \mathrm{yr}$ at the bcginning of the experiment (Figure 9b), and the initial topography is halved after about 5 m.y. For $k=10^{3} \mathrm{~m}^{2} / \mathrm{yr}$ the range topography is halved after about $15 \mathrm{~m}$.y. Once the crust and Moho topographics have been smoothed by surface processes and subsurface deformation, the system evolves again toward the regime of homogeneous thickening.

\section{Case 3, Shortening and Erosion: "Mountain Growth"}

Mountain growth can occur provided that denudations are not too rapid nor too slow compared to the shortening rate. We performed a set of experiments starting from points in the "subsurface collapse" regime, and we then gradually increased the intensity of erosion, kceping the shortening rate constant. If crosion is not active enough, the range decays as a result of subsurface deformation. At some critical value of $k$ a regime of

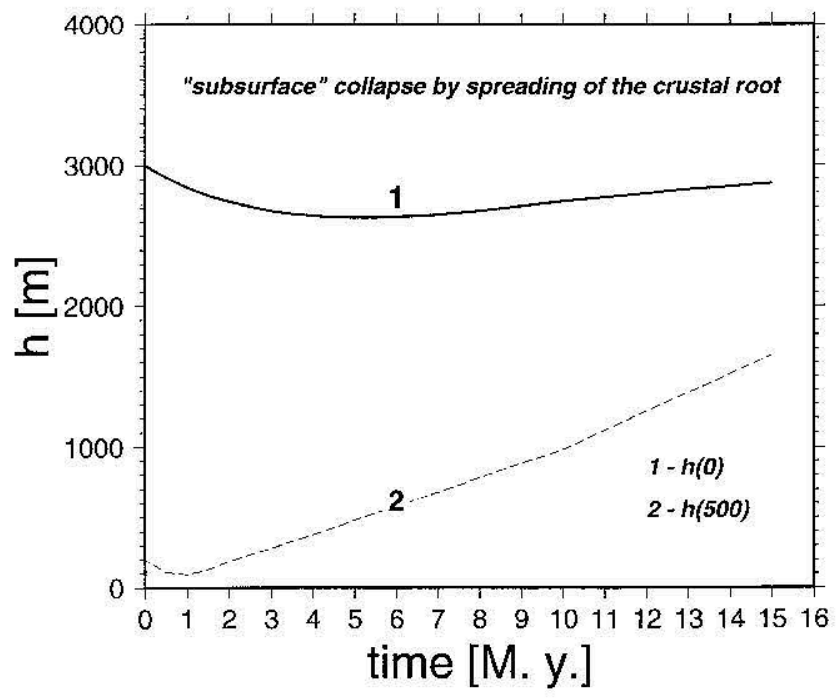

Figure 8b. Evolution of elevation $h$ at axis of the range ( $x=$ $0 \mathrm{~km})$ and in the lowland $(x=500 \mathrm{~km})$ as a function of time. Flexural and flow adjustment occurs during the first 1-2 m.y. 

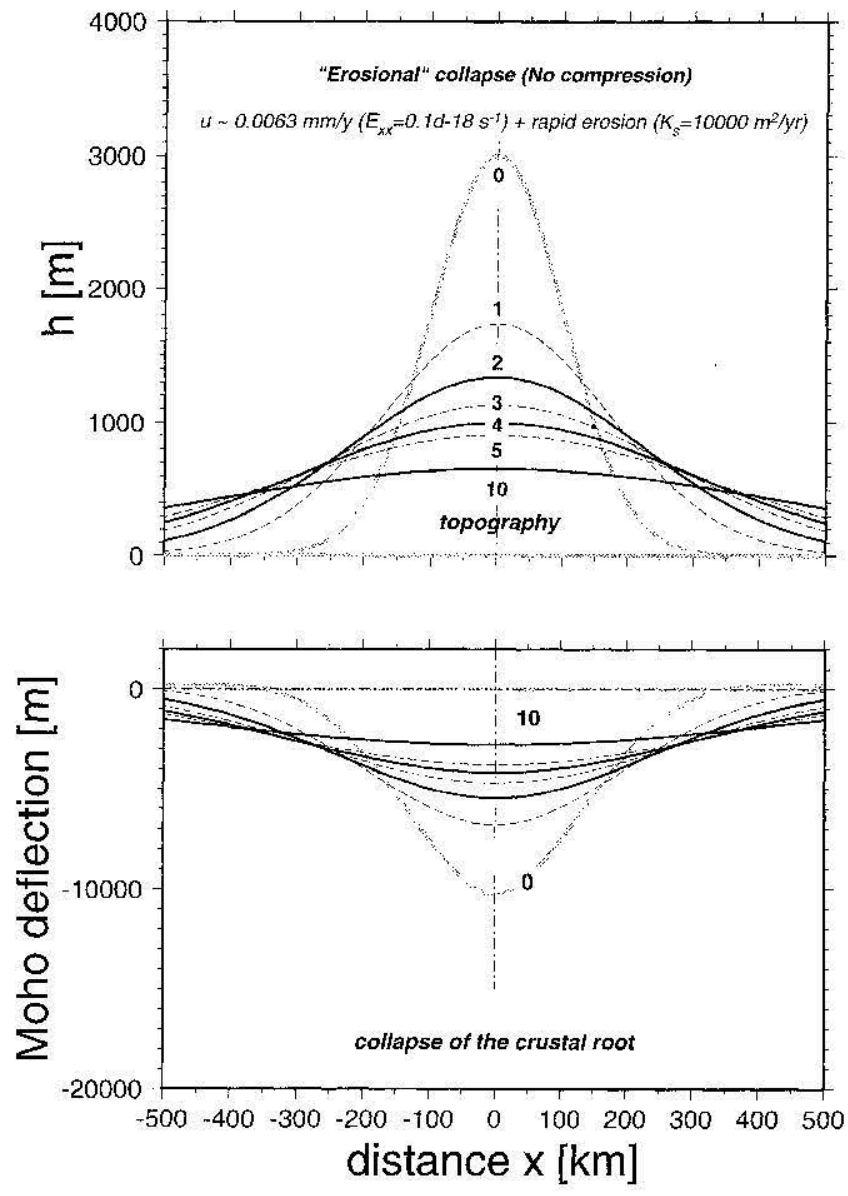

Figure 9a. A case example of "erosional collapse" of topography in the absence of horizontal shortening. Evolution (top) of topography and (bottom) of the crustal root with rapid $(k=$ $10^{4} \mathrm{~m}^{2} / \mathrm{yr}$ ) erosion.

dynamical coupling can settle in which the relicf of the range can grow (Figure 10a). Similarly, we may start from a statc of "erosional collapse," kecp the rate of erosion constant, and gradually increase the rate of shortening. We get that for low shortening rates, erosion can still erase the range topography, but at some critical value of the shortening rate a coupled regime can settle (Figure 10a). In the coupled regime the lower crust flows toward the crustal root (Figure 10b), and the resulting flux exceeds the amount of material removed from the range by surface processes. Tectonic uplift below the range exceeds denudation (Figure 10c) so that the elevation of the crest increases with time (Figure 10d). In this "mountain growth" regime the distribution of deformation remains hetcrogeneous in the long term. High strains in the lower and upper crust are localized below the range allowing for crustal thickening. The crust in the lowland also thickens owing to sedimentation but at a smaller rate than beneath the range (Figure 10c). Figure 11 shows that the rate of growth of the elevation at the crest, $d h / d t(x=0)$, for different experiments in the "mountain growth regime." First we see that for a given cxperiment the evolution is far from monotonic in general. There are oscillations probably related to fluctuations around a dynamic equilibrium in which eroded material and inward flow in the lower crust rate by a constant ratio. Such a dynamic equilibrium occurs for experiment 1. If denudation is too rapid,

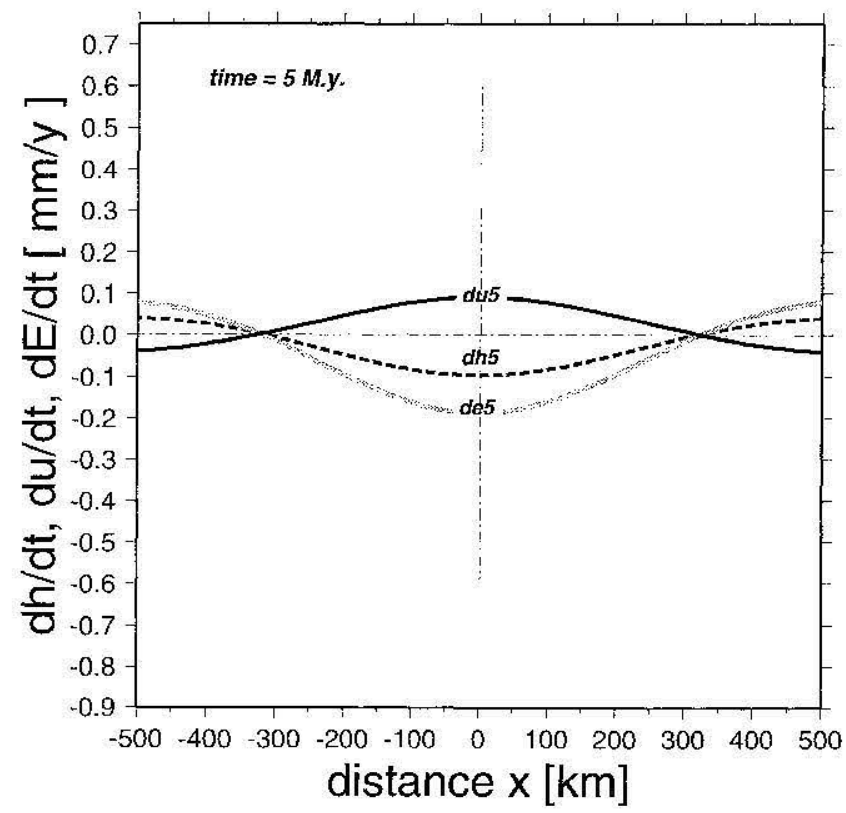

Figure 9b. Rates of denudation (de5), surface uplift ( $d h 5$ ), and tectonic uplift $(d u 5), t=5 \mathrm{~m} . \mathrm{y}$. with moderate erosion $\left(k=10^{4} \mathrm{~m}^{2} / \mathrm{yr}\right)$.

the topography flattens. Since the slopes of the topography and Moho are reduced inward flow in the lower crust can proceed more rapidly, inducing a renewed uplift. Such oscillations are particularly clcar in cxperiment 3 . Comparison of the different experiments indicates that the behavior of the system is very sensitive to small changes of parameters. We did not explore the dynamical behavior of the system in the coupled regime, but we suspect that some chaotic behavior may arise.

The results for different experiments are summarized in Figure 12. As a convention a given experiment, corresponding to a given mass diffusivity and a given shortening rate (or

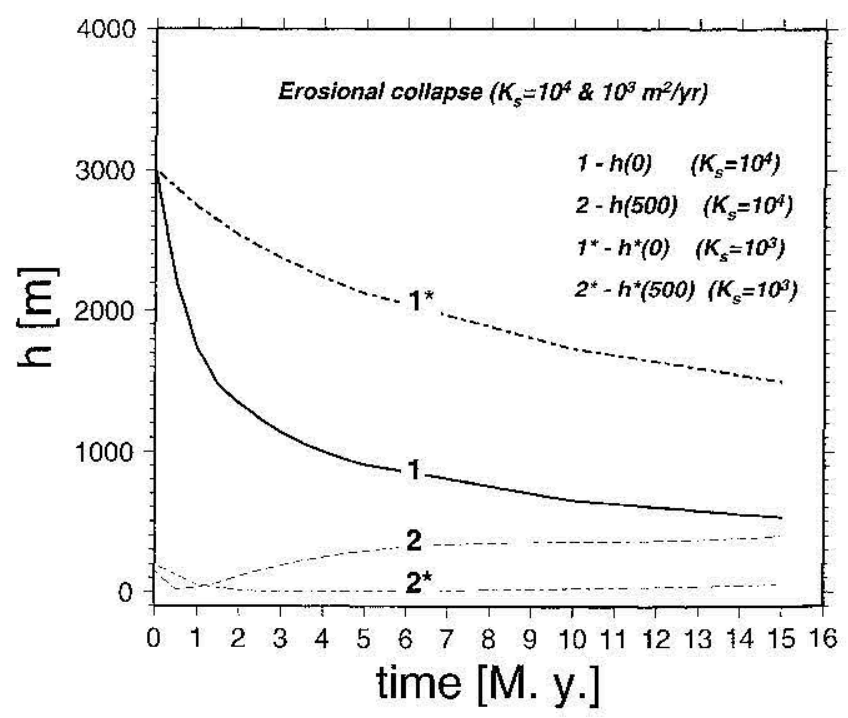

Figure 9c. Evolution of the elevation $h$ at the axis of the range $(x=0 \mathrm{~km})$ and in the lowland $(x=500 \mathrm{~km})$ with rapid $\left(k=10^{4} \mathrm{~m}^{2} / \mathrm{yr}\right)$ and moderate $\left(k=10^{3} \mathrm{~m}^{2} / \mathrm{yr}\right)$ erosion. Faster erosion $\left(k=10^{4} \mathrm{~m}^{2} / \mathrm{yr}\right)$ results in more rapid smoothing of the range and increase of elevation of the forelands. 

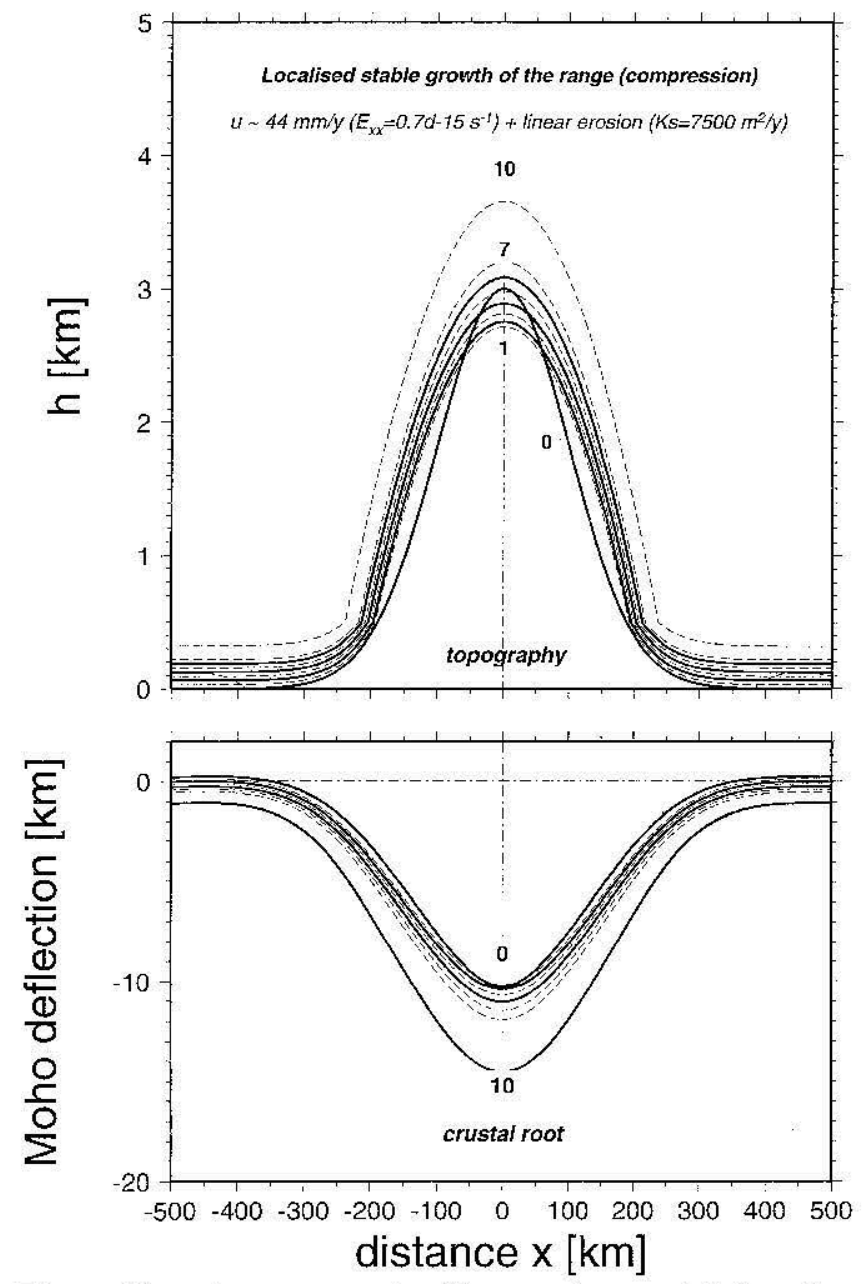

Figure 10a. A case example of "mountain growth." Coupling between erosional and tectonic processes results in a slow localized growth of a range. In this cxample, the scction is submitted to $44 \mathrm{~mm} / \mathrm{yr}$ of shortening, and erosion is relatively intense with a mass diffusivity of $k=7500 \mathrm{~m}^{2} / \mathrm{yr}$. Evolution (top) of topography and (bottom) of crustal root.

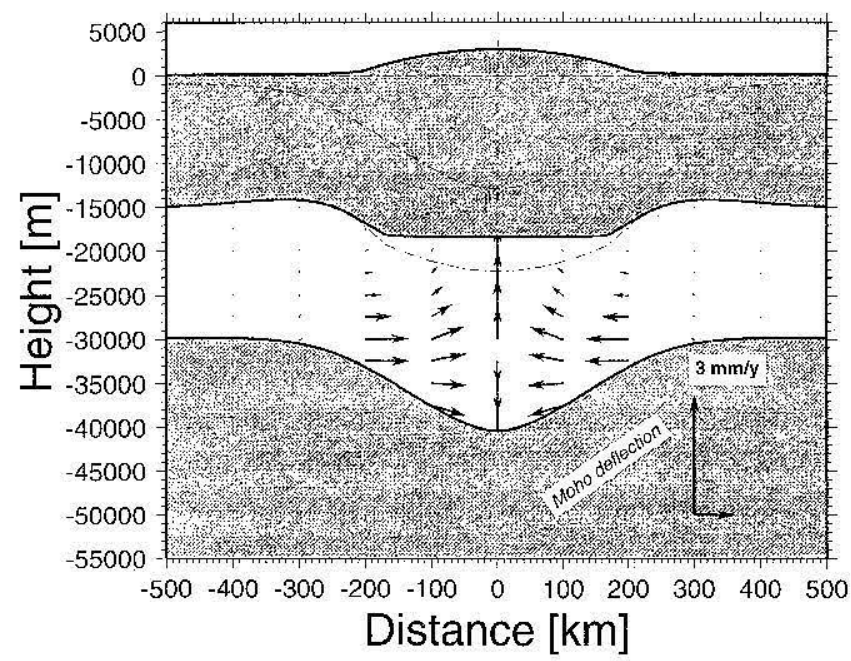

Figure 10b. Flow pattern in lower crust. Dashed line in lower crust corresponds to deflection of lower crust. Solid line is the bottom of competent upper crust. Bending stresses result in thermomechanical "erosion" of bottom of mechanical upper crust. $A$ constant horizontal velocity, corresponding the horizontal velocity at the bottom of the competent crust $\left(y_{13}\right)$ is substracted.

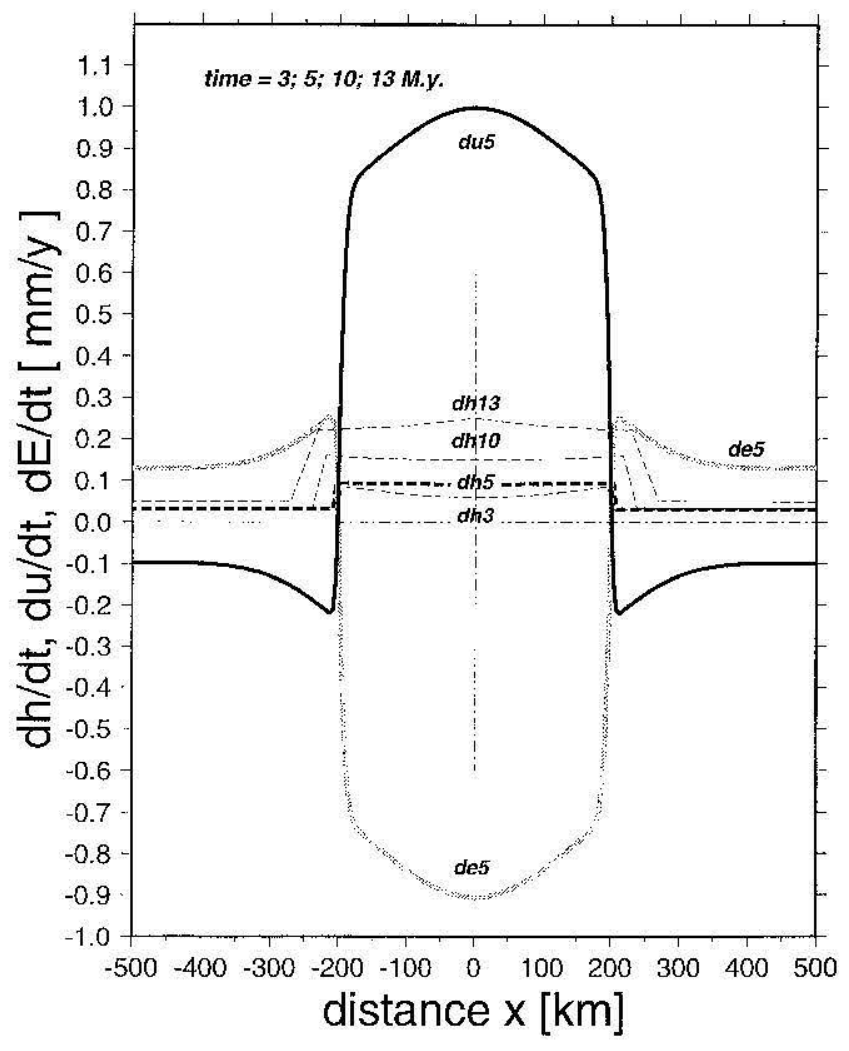

Figure 10c. Rates of denudation (de/dt), surface uplift ( $d h$ / $d t)$, and tectonic uplift $(d u / d t)$. Notations $d h 3, d h 5, d h 10$, etc., correspond to $t=3,5$, and $10 \mathrm{~m} . \mathrm{y}$., etc., respectively. Thick grey line shows initial topography.

average strain rate), is defined to be in the "mountain growth" regime if the relief of the range increases at 5 m.y., which means that clevation at the crest $(x=0)$ increases more rapidly than the clcvation in the lowland $(x=500 \mathrm{~km})$ :

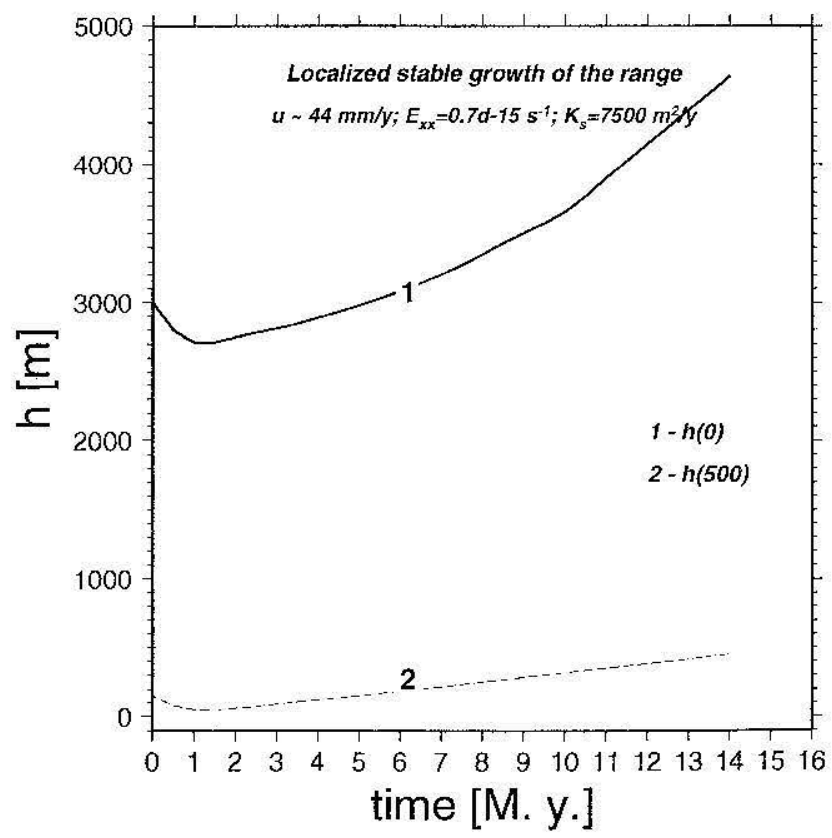

Figure 10d. Fvolution of elevation $h$ at the axis of range $(x=0 \mathrm{~km})$ and in the lowland $(x=500 \mathrm{~km})$ as a function of time. 


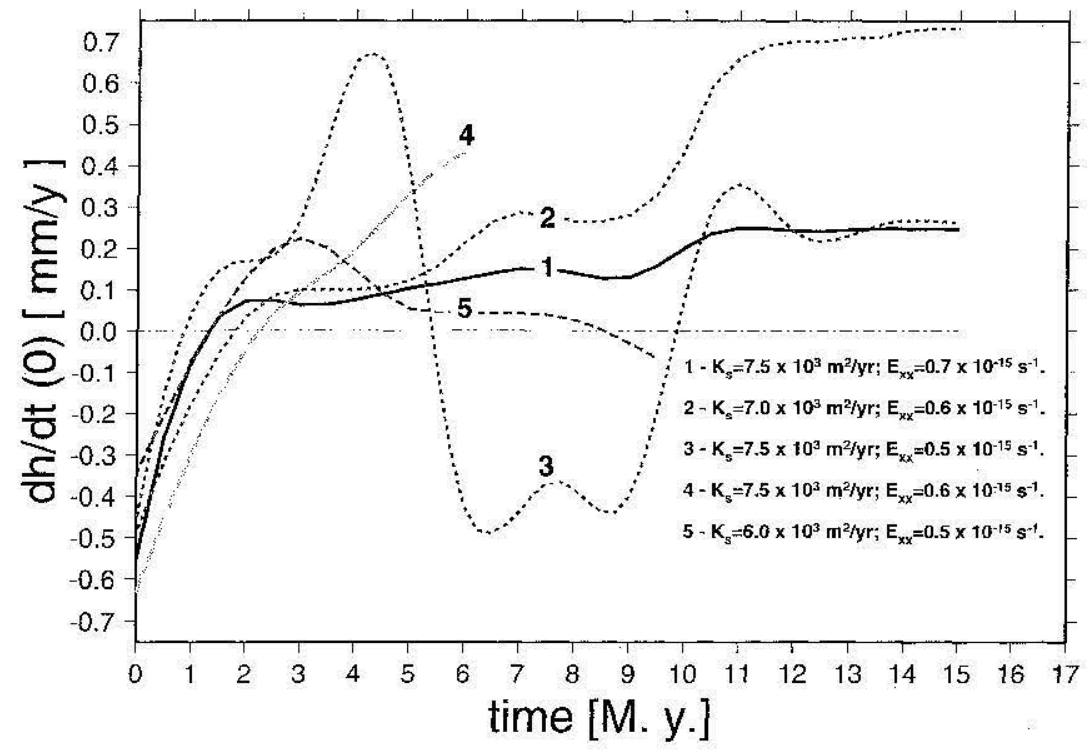

Figure 11. Time cvolution of surface uplift rate $d h / d t(x=0)$ (at axis of the range) for different cases of "mountain growth." An cxperiment is said to be in the "mountain growth" regime if $d h / d t(x=0)$ is positive at $t=5 \mathrm{~m}$.y. All experiments show a rapid rcorganization during the first $1-2 \mathrm{~m}$.y. Curve 1 corresponds to a particular stable growth. In most experiments the growth is rather irregular. This is why two experiments with relatively close initial condition are not necessarily in the same domain, as appears on Figure 12.

$$
d h / d t(0 \mathrm{~km})>d h / d t(500 \mathrm{~km}) \text { at } t=5 \text { m.y. }
$$

Because of the complex dynamic shown in Figure 11, very close experiments appear to be labeled differently. Nevertheless, the "mountain growth," "subsurface collapse," and "crosional collapse" domains can be approximately drawn on this plot. Higher strain rates lead to a decrease of the effective viscosity ( $\mu_{\text {etrl }}$, proportional to $\dot{\varepsilon}^{1 / n-1}$ ) of the non-Newtonian lower crust so that a more rapid crosion is nceded to allow the feedback effect due to surface processes. The mountain growth domain thus corresponds to higher mass diffusivities for higher strain rates (Figure 12).

\section{Coupled Regime and Graded Geometries}

In the coupled regime the topography of the range can be seen to develop into a nearly parabolic graded geometry (Figure 10a). This graded form is attained after 2-3 m.y. and reflects some dynamic equilibrium with the topographic rate of uplift being nearly constant over the range (Figure 10c). Rates of denudation and of tectonic uplift can be seen to be also relatively constant over the range domain (Figure 10c). Geometries for which the denudation rate is constant over the range are nearly parabolic since they are defined by

$$
d e / d t=k d^{2} h / d x^{2}=C_{2} .
$$

with $C_{2}$ being some constant. Integration of this expression yields a parabolic cxpression for $h$ :

$$
h=\frac{C_{2}}{2 k} x^{2}+C_{1} x+C_{0} .
$$

The graded gcometries obtained in the experiment slightly deviate from parabolic curves because they do not exactly correspond to uniform denudation over the rangc. This simple consideration does, however, suggest that the overall shape of graded geometries is primarily controlled by the erosion law.

We made computations with nonlinear erosion laws (cqua- tion (4)). For a given shortening rate, experiments that correspond to similar crosion rates over the range lead to the same evolution ("erosional collapse," "subsurface collapse," or "mountain growth") whatever the erosion law. It thus appears that the cmergence of the coupled regime does not depend on a particular erosion law but rather on the intensity of crosion relative to the effective viscosity of the lower crust. By contrast the graded geometries obtained in the mountain growth re-

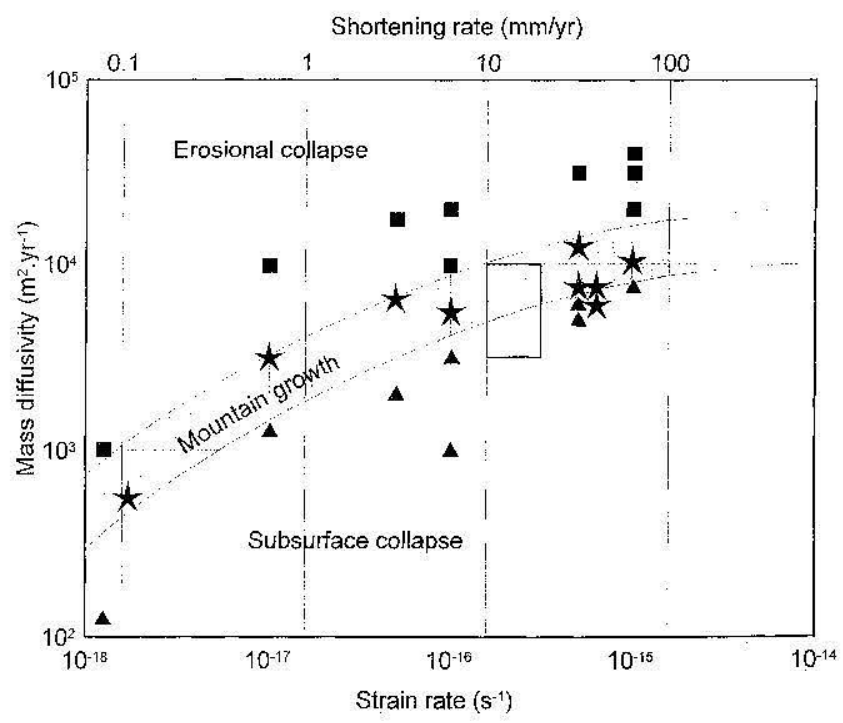

Figure 12. Three major regimes of shortening (log-log plot of $k$-strain rate dependence). Squares correspond to experiments with the "erosional" collapse; triangles correspond to that of the "subsurface" collapse. The area (stars) between the triangles and squares corresponds to regime of "mountain growth." The box corresponds approximately to the Tien Shan as inferred from the $1-2 \mathrm{~cm} / \mathrm{yr}$ shortening rate and the $0.2-0.5$ $\mathrm{mm} / \mathrm{yr}$ denudation rate. 

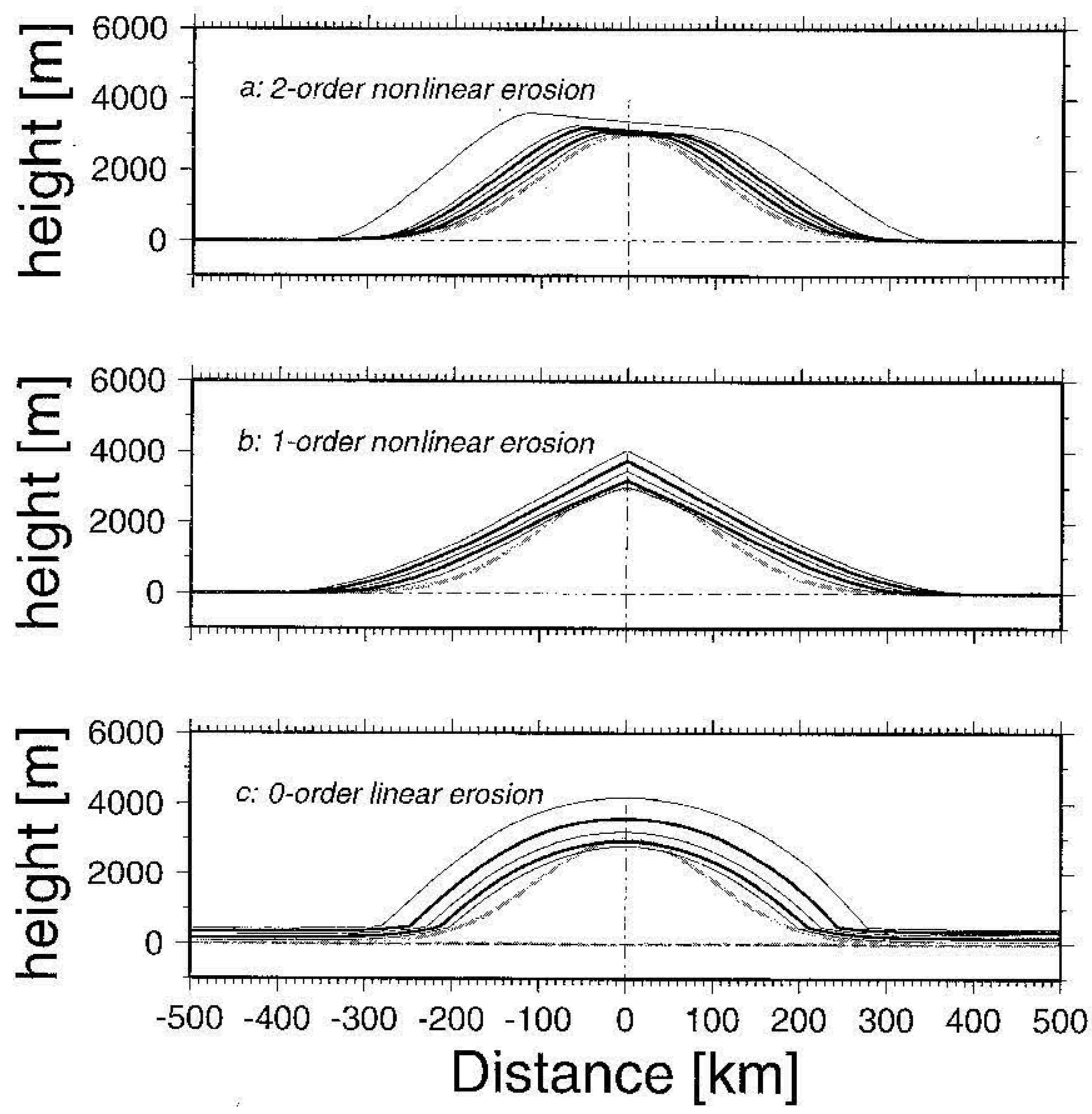

Figure 13. Comparison of different geometries obtained in the coupled regime for various models of erosion. The section is submitted to $44 \mathrm{~mm} / \mathrm{yr}$ horizontal shortening. Thick grey line shows initial topography. After rapid evolution during the first 2 m.y. the range topography gradually increases with time. (a) Secondorder nonlinear erosion model with asymmetric boundary conditions (vertical force $Q_{x}=2 \times 10^{12} \mathrm{~N}$ per unit length is applied on the left edge of plate). The curves correspond to 1, 2, 3, 4, 5, and 10 m.y. (b) First-order nonlinear erosion model. The curves correspond to 1,2,3,4, and $5 \mathrm{~m}$.y. (c) Linear diffusion model of erosion. The curves correspond to $1,2,3,4$, and 5 m.y.

gime strongly depend on the erosion law (Figure 13). The first-order diffusion law leads to triangular ranges, whereas the second-order diffusion leads to plateau-like geometries. It appears that the graded geometry of a range may reflect the macroscopic characteristics of erosion. It might therefore be possible to infer empirical macroscopic laws of erosion from topographic profiles across mountain belts provided that they can be assumed to be graded.

\section{Sensitivity to the Rheology and Structure of the Lower Crust}

The experiments shown above have been conducted assuming a quartz rheology for the whole crust that is particularly favorable for channel flow in the lower crust. In order to show that the coupled regime of mountain growth can also occur assuming a less ductile lower crust, we also conducted some experiments assuming more basic lower crustal compositions (diabase, quartz-diorite) (Table 1). Even with a relatively strong lower crust the coupled regime altowing for mountain growth can settle (Figure 14). The effect of a less viscous lower crust is that for a given shortening rate, lower rates of erosion are required to allow for the growth of the initial mountain. The domain delining the "mountain growth" regime in Figure 12 would thus be shifted toward smaller mass diffusivities when a stronger lower crust is considered. The graded shape obtained in this regime does not differ from that obtained with a quarlz rheology for the lower crust (Figure 14). Estimates of the yicld strength of the lower crust near the Moho boundary for thermal ages from 0 to 2000 m.y. made by Burov and Diament [1995] suggest that whatever rheology is considered, a crust thicker than about $40-50 \mathrm{~km}$ implies a low-viscosity channel in the lower crust. The regime that we have cvidenced in our numerical simulations could therefore exist for a wide range of conditions.

\section{Comparison With the Tien Shan}

Although the Tien Shan may not appear as a generic mountain range, we comparc our modeling with that particular range because rates of deformation and of crosion have been estimated from previous studies [e.g., Avouac et al, 1993; F. Métivier and Y. Gaudemer, Mass transfer between eastern Tien Shan and adjacent basins: Constraints on regional tectonics and topography, submitted to Geophysical Joumal Intemational, 1996] and because the range has a relatively simple 2-D geometry. The Tien Shan is the largest and most active mountain range in central Asia (Figure 1a). It extends for nearly $2500 \mathrm{~km}$ between the Kyzil Kum and Gobi deserts, with peak rising to more than $7000 \mathrm{~m}$. The high level of seismicity in this century [Molnar and Deng, 1984] and deformation of Holocene alluvial formations [Avouac et al., 1993] would indicatc a rate of shortening of the order of $1 \mathrm{~cm} / \mathrm{yr}$. In fact, the shortening 

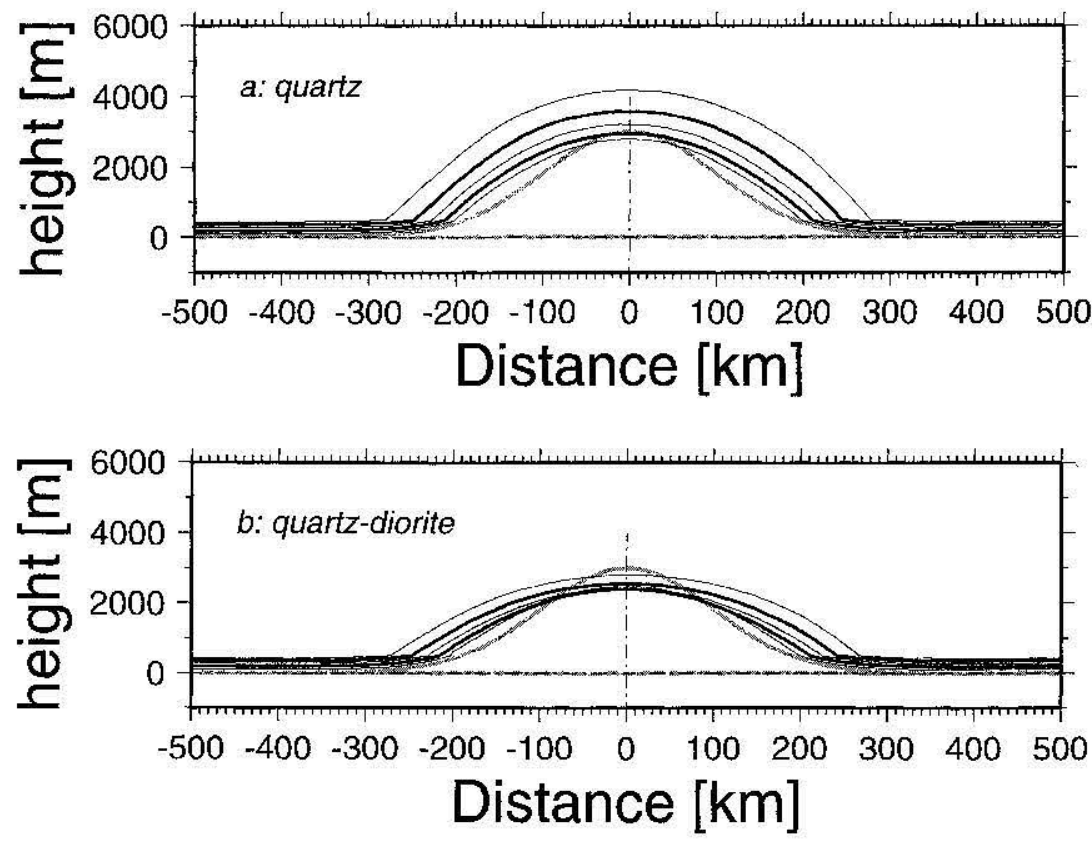

Figure 14. Influence of lower crustal rheology (sce Table 1 for parameters) for $1.2 \mathrm{~cm} / \mathrm{yr}$ shortening. After rapid evolution during the first $2 \mathrm{~m}$.y. the range topography gradually increases with time. (a) Quartzdominated lower crust; (b) "stronger" quartz-diorite lower crust. The two experiments are in the mountain growth regime. The curves correspond to $0,1,2,3,4$, and 5 m.y.

rate is thought to increase from a few millimeters per year east of $90^{\circ} \mathrm{E}$ to about $2 \mathrm{~cm} / \mathrm{yr}$ west of $76^{\circ} \mathrm{E}$ [Avouac et al., 1993]. Clockwise rotation of the Tarim Basin with respect to Dzungaria and Kazakhstan would be responsible for this westward increase of shortening rate as well as of the increase of the width of the range (Figure 1a) [Chen et al., 1991; Avouac et al., 1993]. The gravity studies by Burov [1990] and Burov et al. [1990] also suggest westward decrease of the integrated strength of the lithosphere. The westward increase of the topographic load and strain rate could be responsible for this mechanical weakening. The geological record suggests a rather smooth morphology with no great clevation differences and low clevations in the Tertiary and that the range was reactivated in the middlc Tertiary, probably as a result of the IndiaAsia collision [e.g., Tapponnier and Molnar, 1979; Hendrix et al., 1992]. Fission track ages from detrital appatite from the northern and southern Tien Shan would place the reactivation at about 20 m.y. [Hendrix et al., 1994; E. Sobel and T. A. Dumitru, Exhumation of the margins of the western Tarim Basin during the Himalayan orogen, submitted to Tectonics, 1995]. Such an age is consistent with the middle Miocene influx of clastic material and more rapid subsidence in the forelands [Hendrix et al., 1992]. The present difference of elevation of about $3000 \mathrm{~m}$ between the range and the lowlands (Figure $1 \mathrm{~b}$ ) would therefore indicate a mean rate of uplift of the topography, during the Cenozoic orogeny, of the order of $0.1-0.2$ $\mathrm{mm} / \mathrm{y}$. The forcland basins have collected most of the material removed by erosion in the mountain. Sedimentary isopachs indicate that $1.5 \pm 0.510^{6} \mathrm{~km}^{3}$ of material would have been eroded during the Cenozoic orogeny (F. Métivier and Y. Gaudemer, submitted manuscript, 1996), implying erosion rates of $0.2-0.5 \mathrm{~mm} / \mathrm{yr}$ on average. The tectonic uplift would thus have been of $0.3-0.7 \mathrm{~mm} / \mathrm{yr}$ on average. On the assumption that the range is approximately in local isostatic equilibrium [Burov et al., 1990; Ma, 1987], crustal thickening below the range has absorbed 1.2-4 $\times 10^{6} \mathrm{~km}^{3}$ (Métivier and Gaudemer, submitted manuscript, 1996). Crustal thickening would thus have accommodated $50-75 \%$ of the crustal shortening during the Cenozoic orogeny, with the remaining $25-50 \%$ having been fed back to the lowlands by surface processes. Given the geometry of the range, the $0.2-0.5 \mathrm{~mm} / \mathrm{yr}$ denudation rate implies a mass diffusivity of the order of $2 \times 10^{3}$ to $10^{4} \mathrm{~m}^{2} / \mathrm{yr}$. These values actually place the Tien Shan in the "mountain growth" regime on the plot in Figure 12. We therefore conclude that the localized growth of a range like the Tien Shan could actually result from the coupling between surface processes and horizontal strains. We do not dispute the possibility for a complex mantle dynamics beneath the Tien Shan as has been inferred by various geophysical investigations [Vinnik and Saiphekova, 1984; Makeyeva et al., 1992; Roecker et al., 1993], but wc contend that this mantle dynamics has not necessarily been the major driving mechanism of the Cenozoic Tien Shan orogeny.

\section{Conclusions and Implications}

This study demonstrates that denudation could exert some control on the development of an intracontinental mountain belt. Depending on the intensity of the surface processes, horizontal compression of a 2-D section of continental lithosphere with some initial topographic irregularity can lead either to strain localization below a growing range or to distributed thickening. Homogeneous thickening occurs when erosion is either too strong, in which case any topographic irregularity is rapidly washed out by surface processes, or too weak, in which case the crustal root below the range spreads out laterally with formation of a flat "pancake-shaped" topography. In our modeling, mountain growth results from dynamical coupling between the advection at the surface by surface processes and at 


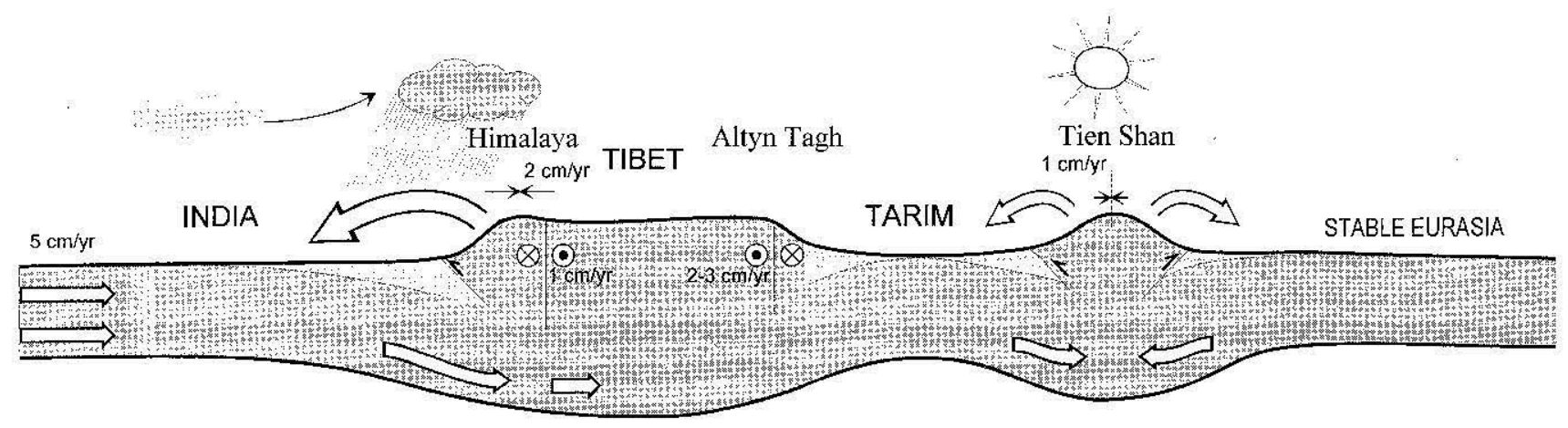

Figure 15. Sketch illustrating the India-Asia collision and the possible influence of climate on the distribution of strain in central Asia. Although the Himalaya and the Tien Shan ranges are probably submitted to similar horizontal forces, the Himalaya absorbs about $2 \mathrm{~cm} / \mathrm{yr}$ of N-S shortening, while the Tien Shan absorbs only about $1 \mathrm{~cm} / \mathrm{yr}$. The higher strain rates in the Himalaya may be related to the monsoonal climate that is much more erosive than the climate in the Tien Shan area.

depth by flow in the lower crust. Intracontinental orogenies could arise from such a coupling without the help of any other source of strain localization.

Deformation of a continent may thus be very sensitive to surfacc processes. The way central Asia has absorbcd indentation of India may somehow reflect this sensitivity. Numerical models of continental indentation based on continuum mechanics, but that neglect surface processes, predict a broad zonc of crustal thickening, resulting from nearly homogeneous strain that would have propagated away from the indentor [England and Houseman, 1986; Houseman and England, 1986; Vilotte et al., 1982]. In fact, long-lived zones of localized crustal shortening have been maintained (in particular, along the IHmalaya, at the front of the indentor, and the Tien Shan, well north of the indentor), and broad zones of thickened crust have resulted from sedimentation rather than from horizontal shortening (in particular in the Tarim Basin and to somc cxtent in some Tibetan basins such as the Tsaidam). Present kinematics of active deformation in central Asia corroborates a highly heterogeneous distribution of strain. The $5 \mathrm{~cm} / \mathrm{yr}$ convergence between India and stable Eurasia is absorbed by lateral cxtrusion of Tibet and crustal thickening with crustal thickening accounting for about $3 \mathrm{~cm} / \mathrm{yr}$ [Avouac and Tapponnier, 1993]. About $2 \mathrm{~cm} / \mathrm{yr}$ would be absorbed in the Himalayas and $1 \mathrm{~cm} / \mathrm{yr}$ in the Tien Shan (Figure 15). The indentation of India into Eurasia has thus induced localized strain below two rclatively narrow zones of active orogenic processes, whilc minor deformation has been distributed elsewhere. Surface processes might be partly responsible for this highly heterogencous distribution of deformation. First, active thrusting along the Himalaya and in the Tien Shan may have been sustained during most of the Cenozoic thanks to continuous erosion. Sccond, the broad zone of thickened crust in central Asia has resulted in part from the redistribution of the sediments eroded from the localized growing reliefs. Morcover, it should be observed that the Tien Shan experiences a relatively arid intracontinental climate, while the Himalaya is cxposed to a very erosive monsoonal climate. Although rheological differences might also be advocated, this climatic disparity may cxplain why the Himalaya absorbs twice as much horizontal shortening as the Tien Shan, while tectonic forces are probably similar. In addition, the nearly equivalent climatic conditions on the northern and southern flanks of the Tien Shan might have favored the development of a ncarly symmetrical range.
By contrast the much more erosive climatic conditions on the southern than on the northern flank of the Himalaya may have favored the development of systematically south vergent structures. While the Indian upper crust would have been delaminated and brought to the surface of erosion by north dipping thrust faults, the Indian lower crust would have flowed below Tibet (Figure 15). Surface processes might therefore have facilitated injection of lindian lower crust below Tibet as was proposed by Zhao and Morgan [1985]. This would explain crustal thickening of Tibet with minor horizontal shortening in the upper crust and minor sedimentation.

We thus suspect that climatic zonation in Asia has exerted some control on the spatial distribution of the intracontinental strain induced by the India-Asia collision. The interpretation of intracontinental deformation should not be thought of only in terms of boundary conditions induced by global plate kinematies but also in terms of global climate. Climate might therefore be considered as a forcing factor of continental tectonics.

\section{Appendix A: Model of Flexural Deformation of the Competent Cores of the Brittle-Elasto- Ductile Crust and Upper Mantle}

Deformation of the competent layers in the crust and mantle, as defined from the BED rheology (Figures 3 and 4) in response to redistribution of loads by surface processes or flow in the lower crust, is computed using plate equilibrium equations [Burov and Diament, 1995]:

$$
\begin{aligned}
& \frac{\partial}{\partial x}\left[\frac{\partial}{\partial x}\left(\frac{E}{12\left(1-v^{2}\right)}\right)\left(\tilde{T}_{e}^{3}(\phi) \frac{\partial^{3} w(x, t)}{\partial x^{2}}\right)+\widetilde{T}_{x}(\phi) \frac{\partial w(x, t)}{\partial x}\right] \\
& +p_{-}(\phi) w(x, t)-p_{+}(x, t)=0 \\
& \tilde{T}_{c}(\phi)=\left[\frac{\tilde{M}_{x}(\phi)}{L}\left(\frac{\partial^{2} w(x, t)}{\partial x^{2}}\right)^{-1}\right]^{1 / 3} \\
& \tilde{M}_{\mathrm{r}}(\phi)=-\sum_{i=1}^{n} \sum_{j=1}^{m_{i}} \int_{y_{i j}(\phi)}^{y_{i j}^{+}(\langle)} \sigma_{x i}^{(j)}(\phi) y_{i}^{*}(\phi) d y \\
& \tilde{T}_{x}(\phi)=-\sum_{i=1}^{n} \sum_{j-1}^{m_{i}} \int_{y_{i i}^{-}(\phi)}^{y_{i j}^{\prime}(t, j)} \sigma_{s x}^{(j)}(\phi) d y \\
& \sigma_{x x}^{(j)}(\phi)=\operatorname{sign}\left(\varepsilon_{x x}\right) \min \left[\left|\sigma^{f}\right|, \sigma_{x x}^{e(j)}(\phi)\right]
\end{aligned}
$$




$$
\sigma_{x x}^{(i j)}(\phi)=\left(y_{i}^{*}(\phi) \frac{\partial^{2} w(x, t)}{\partial x^{2}}\right) E_{i}\left(1-v_{i}^{2}\right)^{-1}
$$

where $w=w(x, t)$ is the vertical plate deflection (related to the regional isostatic contribution to tectonic uplift $d u_{i s}$ as $\left.d u_{i s}=w(x, t)-w(x, t-d t)\right) ; \phi \equiv\left\{x, y, w, w^{\prime}, w^{\prime \prime}, t\right\}$; $y$ is positive downward; $y_{i}^{*}=y-y_{n i}(x) ; y_{n i}$ is the depth to the $i$ th neutral (i.e., stress-free, $\left.\sigma_{x x}\right|_{y_{i}, 0}=0$ ) plane; and $y_{i}^{-}(x)=$ $y_{i}, y_{i}^{+}(x)=y_{i}^{+}$are the respective depths to the lower and upper low-strength interfaces (see Figure $3 \mathrm{~b}$ ). The strength $\sigma^{f}$ is defined by equation (9); $n=1$ refers to the competent crust and $n=2$ refers to the competent mantle; $m_{i}$ is the number of "welded" (continuous $\sigma_{x x}$ ) sublayers in the $i$ th detached layer; $p_{-} w$ is a restoring stress $\left(p_{-} \sim\left(\rho_{m}-\rho_{c 1}\right) g\right)$ and $p^{+}$ is a sum of surface and subsurface loads. The most important contribution to $p^{+}$is from the load of topography, that is, $p^{+} \sim \rho g h(x, t)$, where the topographic height is $h(x, t)$. The thickness of the $i$ th competent layer is $y_{i}{ }^{\prime}-y_{i}^{-{ }^{-}}=\Delta h_{i}(x)$. The term $\partial^{2} w / \partial x^{2}$ in (Al) is inversely proportional to the radius of plate curvature $R_{x y} \approx-\left(\partial^{2} w / \partial x^{2}\right)^{-1}$. Thus the higher the local curvature of the plate is, the lower the local integrated strength of the lithosphere is. The integrals in (A1) are defined through the constitutive laws (5)-(7) and (9)-(10) relating the stress $\sigma_{x x}$ and strain $\varepsilon_{x x}=\varepsilon_{x x}(\phi)$ in a given segment $\{x, y\}$ of a plate. Note that the value of the effective elastic thickness $\widetilde{T}_{e}(\phi)$ holds only for the given solution for plate deflection $w$. The nonlinear equations (A1a)-(A1f) are computed using an iterative approach based on finite difference approximation (block matrix presentation) with linearization by Newton's method [Burov and Diament, 1992]. The procedure starts from calculation of clastic prediction $w_{c}(x)$ for $w(x)$, that gives predicted $w_{e}(x),(\partial w / \partial x)_{e}(x),\left(\partial^{2} w / \partial x^{2}\right)_{e}$, used to derive solutions for $y_{i j}(\phi), y_{i j}^{+-}(\phi)$, and $y_{n i}(\phi)$ that satisfy (5), (6), (7), and (10). Corrected solutions for $\tilde{M}_{x}$ and $\widetilde{T}_{x}$ are deduced and used to obtain $\tilde{T}_{e}$ for the next iteration. At this stage we use gradual loading technique to avoid numerical oscillations. The accuracy is checked through back-substitution of the current solution in (A1) and calculation of the discrepancy between the right and left sides of (A1). For the boundary conditions on the ends of the plate we use commonly inferred combination of plate boundary shearing force $Q_{x}(0)$,

$$
\tilde{Q}_{x}(\phi)=-\sum_{i=1}^{n} \sum_{j-1}^{m i} \int_{y_{i j}^{-i}(\phi)}^{y_{i j}^{-}(\phi)} \sigma_{n j}^{(j)}(\phi) d y,
$$

and plate boundary moment $M_{x}(0)$ (in the case of broken plate) and $w=0, \partial w / \partial x=0$ (and $h=0, \partial h / \partial x=0$ ) at $x \rightarrow \pm \infty$.

\section{Appendix B: Model of Flow in the Ductile Crust}

Flow in the low-viscosity crustal channel is computed in a way similar to the Couette flow model of Lobkovsky [1988], Lobkovsky and Kerchman [1991] (hereafter referred as LK), or Bird [1991]. Our formulation can allow computation of different types of flow ("symmetrical," Poiseuille, Couette). In the numerical experiments shown in this paper we consider only cases with a mixed Couette/Poiseuille/symmetrical flow, but we also checked our formulation by comparison with that of LK for a Couette flow. The low-viscosity crustal channel is bounded by the competent layers in the crust at the top and in the mantle at the bottom. Flexure of these layers will drive flow in the lower crust. In turn, changes of the thickness of the lower crustal channel, $\Delta h_{c: 2}=\Delta h_{0}(x, 0)+\bar{h}+w$, will be compensated by deflection of the Moho, which depth is $h c(x, t)=$ $T_{r}(x, t)=\Delta h_{c: 2}+h_{c \cdot 1}$, and of the upper crust. These deflections are assumed instantaneous and are computed according to Appendix A. Note that the topography of the upper boundary of the lower crustal channel, $\tilde{h}$, does not mimic topographic variation at the surface, $h: \tilde{h}(x, t)-\widetilde{h}(x, t-d t)=$ $d u-d y_{13}$, where $d y_{13}=y_{13}(\phi, t)-y_{13}(\phi, t-d t)$ is the change of the depth of the lower boundary of the elastic core in the upper crust due to changes of deviatoric stresses (as shown in Figure 3b).

The equations governing the creeping flow of an incompressible fluid, in Cartesian coordinates, are, in addition to equations (7) and (8),

$$
\begin{gathered}
-\frac{\partial \sigma_{x x}}{\partial x}+\frac{\partial \tau_{x y}}{\partial y}+F_{x}=0 ; \quad-\frac{\partial \sigma_{y y}}{\partial y}+\frac{\partial \tau_{x y}}{\partial x}+F_{y}=0 \\
\sigma_{x x}=-\tau_{x x}+p=-2 \mu \frac{\partial u}{\partial x}+p \\
\sigma_{x y}=\tau_{x y}=\mu\left(\frac{\partial u}{\partial y}+\frac{\partial v}{\partial x}\right) \\
\sigma_{y y}=-\tau_{y y}+p=-2 \mu \frac{\partial v}{\partial x}+p \\
\frac{\partial u}{\partial x}+\frac{\partial y}{\partial y}=0
\end{gathered}
$$

Where $\mu$ is the depth-dependent effective viscosity, $p$ is pressure, $u$ and $v$ are the horizontal and vertical components of the velocity $\mathbf{v}$, respectively; $F$ is the body force due to gravity; $u=\partial \psi / \partial y$ is the horizontal component of velocity of the differential movement in the ductile crust; $v=-\partial \psi / \partial x$ is its vertical component; and $\partial u / \partial y=\dot{\varepsilon}_{c 20}$ is a component of shear strain rate due to the differential movement of the matcrial in the ductile crust (the components of the strain rate tensor are, consequently, $\dot{\varepsilon}_{11}=2 \partial u / \partial x ; \dot{\varepsilon}_{12}=\partial u / \partial y+$ $\left.\partial v / \partial x ; \dot{\varepsilon}_{22}=2 \partial v / \partial y\right)$.

Within the low-viscosity boundary layer of the lower crust, the dominant basic process is simple shear on horizontal plancs, so the principal stress axes are dipped approximately $\pi / 2$ from $x$ and $y$ (hence $\sigma_{y y}$ and $\sigma_{x x}$ are approximatcly cqual). Then, the horizontal component of quasi-static stress equilibrium equation div $\sigma+\rho g=0$, where tensor $\sigma$ is $\sigma=\tau-P \mathbf{I}$ (I is identity matrix), can be locally simplified yielding thin layer approximation [e.g., Lobkovsky, 1988; Bird, 1991]:

$$
\frac{\partial \tau_{x y}}{\partial y}=\frac{\partial p}{\partial x}-F_{x}=-\frac{\partial \tau_{y y}}{\partial x} .
$$

An effective shear strain rate can be derived $\dot{\varepsilon}_{x y}=$ $\sigma_{x y} / 2 \mu_{e f f}$; therefore, according to constitutive relation (7), horizontal velocity $u$ in the lower crust is

$$
\begin{aligned}
u(\tilde{y}) & =\int_{0}^{\bar{y}} 2 \dot{\varepsilon}_{x y} \partial \tilde{y}+C_{1} \\
& =\int_{0}^{\vec{y}} 2^{n} A^{*} \operatorname{cxp}\left(-H^{*} / R T(y)\right)\left|\tau_{x y}\right|^{n-1} \tau_{x y} \partial \tilde{y}+C_{1} .
\end{aligned}
$$


Here $\tilde{y}=y-y_{13} ; y_{13}=y_{13}(\phi)$ is the upper surface of the channel defined from solution of the system (A1).

$C_{1}$ is an arbitrary constant of integration defined from the velocity boundary conditions (Figure 4 ); $\tau_{x y}$ is defined from depth integration of (B2). The remote conditions $h=0$, $\partial h / \partial x=0, w=0, \partial w / \partial x=0$ for the strong layers of the lithosphere (Appendix A) are in accordance with the condition for ductile flow: $x \rightarrow \infty: u_{c 2}^{+}=u_{c} ; u_{c 2}=u_{m} ; \partial p / \partial x=0$, $\partial p / \partial y=\bar{\rho}_{c} \mathrm{~g} ; p=P_{0}$.

The major perturbation to the stress field is caused by slopes of crustal interfaces $\alpha-\partial \tilde{h} / \partial x$ and $\beta \sim \partial w / \partial x$. Thesc slopes are controlled by flexure, isostatic readjustments, surface erosion, and modification of the interfaces by stress and temperature (thermomechanical weakening). In the assumption of small plate deflections the horizontal force associated with variation of the gravitational potential energy due to deflection of Moho $(w)$ is $\rho_{c_{2}} g \tan (\beta) \sim \rho_{c 2} g \sin \beta \sim \rho_{c 2} g \partial w / \partial x$; the vertical component of force is $\sim \rho_{c 2} g \cos \beta \sim \rho_{c 2} g(1-$ $\partial w / \partial x) \sim \rho_{c: 2} g$. The horizontal and vertical force components due to slopes of the upper walls of the channel are $\rho_{c 2} g$ tan $(\alpha) \sim \rho g \sin (\alpha) \sim \rho_{c 2} g d \tilde{h} / d x$ and $\rho_{c 2} g \cos (\beta) \sim \rho_{c 2} g(1-$ $d \tilde{h} / d x$ ), respectively. The equation of motion (Poiseuille/ Couette flow) for a thin layer in the approximation of lubrication theory will be

$$
\begin{gathered}
\frac{\partial \tau_{x y}}{\partial y}--\frac{\partial \tau_{y y}}{\partial x} \approx \frac{\partial p}{\partial x}-\rho_{c 2} g \frac{\partial(\vec{h}+w)}{\partial x} \\
\frac{\partial \tau_{y y}}{\partial y}+\frac{\partial \tau_{y x}}{\partial x}-\frac{\partial p}{\partial y} \approx-\rho_{c 2} g\left(1-\frac{\partial(\tilde{h}+w)}{\partial x}\right) \\
\partial u_{c 2}+\frac{\partial v_{c 2}}{\partial x}=0 .
\end{gathered}
$$

where $p \approx P_{0}(x)+\bar{\rho}_{c} g\left(\vec{y}+y_{13}+h\right)$ and $\bar{\rho}_{c}$ is averaged crustal density. In the case of local isostasy, $w$ and $j w / \partial x$ are approximately 4 times $\left(\bar{\rho}_{c} / \Delta\left(\bar{\rho}_{c}-\rho_{m}\right) \sim 4\right)$ greater than $\tilde{h}$ and $d \tilde{h} / d x$, respectively. The pressure gradient duc to deflection of the Moho is $\rho_{m} g \partial(\tilde{h}+w) / \partial x$. Accounting for the difference of density between the crust and mantle, the effective pressure gradient in the crust is $\left(\rho_{m}-\bar{\rho}_{c}\right) \mathrm{g} \partial(\vec{h}+w) / \partial x$, with $w$ being equal to $\left.\vec{h}\left(\rho_{m}-\bar{\rho}_{c}\right) / \rho_{m}\right)$. In the case of regional compensation (as computed from the system (A1)) the differcnce between $\hat{h}$ and $w$ is reduced by a factor 2 to 3 .

Equations (B3) and (B4) imply

$$
\begin{gathered}
\frac{\partial \tau_{x y}}{\partial y} \approx \frac{\partial p}{\partial x}-\rho_{c 2} g \frac{\partial(\bar{h}+w)}{\partial x} \\
\frac{\partial p}{\partial y} \approx \rho_{c 2} g\left(1-\frac{\partial(\tilde{h}+w)}{\partial x}\right) \\
\frac{\partial u}{\partial y}=2^{n} A^{*}\left(-H^{*} / R T\right)\left|\tau_{x y}\right|^{n-1} \tau_{x y} \\
\frac{\partial v}{\partial y}=-\frac{\partial u}{\partial x} .
\end{gathered}
$$

Assuming small deflections $\left(w / T_{e} \ll L / T_{e}, \tilde{h} \sim 0.2-0.5 w\right.$, where $L$ is the length of the plate), we get $1-\partial(\tilde{h}+w) / \partial x \approx 1$.

Depth integration of (B5) yields the longitudinal and vertical components of the velocity in the lower crust. For example, we have

$$
\begin{gathered}
u=\int_{0}^{h_{c 2}-y_{13}} 2^{n} A^{*} \exp \left(-H^{*} / R T(\tilde{y})\right)\left|\tau_{x y}\right|^{n}{ }^{1} \tau_{x y} \partial \tilde{y} \\
\left.v\right|_{t, 2-y_{13}} ^{h_{12}}=-\partial \partial \int_{0}^{h_{22} y_{13}} u \partial \tilde{y} \approx \frac{\partial(\tilde{h}+w)}{\partial t} .
\end{gathered}
$$

The later equation gives the variation of thickness of the ductilc channel in time (equal to the difference between the vertical flow at the top and bottom boundaries).

The temperature, which primarily controls the effective viscosity of the crust, is much lower in the uppermost and middle portions of the upper crust (at $10-15 \mathrm{~km}$ depth). As a result, the effective viscosity of the middle portions of the upper crust is 2-4 orders higher than that of the lower crust $\left(10^{22}\right.$ to $10^{23}$ Pa s compared to $10^{1 *}$ to $10^{20} \mathrm{~Pa} \mathrm{~s}$, cquations (7) and (8)). Therefore we can consider the reaction of the lower crust to deformation of the upper crust as rapid. For numerical reasons, we cut the interval of variation of the effective viscosity at $10^{19}$ to $10^{24} \mathrm{~Pa}$. Solution for the channel flow implies that the channel is infinite in both directions. In our case the channel is semi-infinite because of the requirement $u=0$ at $x=0$. Vclocity boundary conditions are assumed on the upper and bottom interfaces of the lower crustal channel. Free flow is the inherent lateral boundary condition.

\section{Appendix C: Analytical Formulation for Ascending Crustal Flow}

In this appendix we present computation of the flow under the range, where the thin channcl approximation of Appendix $B$ may not be valid. In a general case of noninertial flow (low Reynolds number) the flow beneath the mountain range can be computed, assuming symmetry with respect to the axis of the range, from the system [Fletcher, 1988; Hamilton et al., 1995]

$$
\begin{gathered}
0=\rho_{c 2} F_{x}-\frac{d p}{d x}+\frac{\partial}{\partial y}\left(2 \mu\left(\left(\begin{array}{c}
\partial u \\
\partial y
\end{array}+\frac{\partial v}{\partial x}\right)\right)\right) \\
0=\rho_{c: 2} F_{y}-\frac{d p}{d y}+\frac{\partial}{\partial x}\left(2 \mu\left(\left(\begin{array}{c}
\partial u \\
\partial y
\end{array}+\frac{\partial v}{\partial x}\right)\right)\right) \\
\frac{\partial u}{\partial x}+\frac{\partial v}{\partial y}=0
\end{gathered}
$$

We define $\partial p / \partial x \approx \partial \vec{p} / \partial x+g\left(\rho_{c 2} \partial w / \partial x+\rho_{c:} \partial(d u) / \partial x\right)$, $d u \approx d \vec{h}$, and $\partial p / \partial y=\partial \tilde{p} / \partial y-g \rho_{c: 2}$, where $\tilde{p}$ is dynamic, or modified, pressure.

The flow is assumed to be Couette/Poiselle flow (Appendix B) away from the symmetry axis (at a distance $a_{l}$ ); $a_{l}$ is equal to 1-2 thicknesses of the channel, depending on channel thickness-to-length ratio. In practice, $a_{l}$ is equal to the distance at which the cquivalent elastic thickness of the crust (as defined by Burov and Diament [1995]) becomes less than $5 \mathrm{~km}$. When the elastic thickness of the crust is so thin, we assume that the upper boundary of the ductile lower crust can be considered free of shear stress. This assumption makes the computation easier. Another more realistic boundary condition would probably modify the flow only in a thin zone at top of the lowviscosity channel in the lower crust.

The remote feeding flux $q$ at $x \rightarrow \pm a_{l}$ is equal to the value of flux obtained from depth integration of the channel source (Couctte flow). The flux $q$ is determined as $q \sim \int u d y$ (per 
unit length in $z$ direction). This flux fecds the growth of the topography and decpening of the crustal root. Combination of two flow formulations is completed using continuity equations [Huppent, 1982]

$$
\begin{gathered}
\int \frac{\partial y}{\partial y} d y+\frac{\partial}{\partial x}\left(\int u d y\right)=0=\frac{\partial(\tilde{h}+w)}{\partial t}+\frac{\partial q}{\partial x} \\
\left.q\right|_{x=t\left(t, x \leqslant a_{i}\right.}=\left.q\right|_{x=u t, x=a_{i}} \\
\int_{0}^{t r(\phi)}(\tilde{h}+w) d x+\int_{u_{i}(t)}^{x}(\tilde{h}+w) d x=q t^{\theta},
\end{gathered}
$$

where $\theta=1$ in our case and on left-hand side of $(\mathrm{C} 2 \mathrm{c})$ the first term is ascending flow and the second term is channel flow. With that we can combine solutions for horizontal flow far off the mount axis (Couctte/Poiscuille flow) with solutions for ascending flow below the mount [e.g., Hansen and Kelmanson, 1994]. Assuming a new local coordinatc system $x^{\prime}=x, y^{\prime}=$ $-y-\left(h_{c 2}+\left(h_{c 2}-y_{13}\right) / 2\right)$, the boundary conditions for the flow ascending near the symmetry axis would be $u=v=$ $0 ; d u / d y^{\prime}=0$ at $x^{\prime}=0, y^{\prime}=0$ (beneath the mount axis). As pointed out by Davies [1994], it is impossible to provide an analytical or simplified semianalytical solution for the case when the viscosity $\mu$ is defined exactly through the power law (7). We therefore assume that the viscosity $(\mu)$ in the ascending flow is constant and equal to $\mu=\vec{\mu}\left(a_{l}\right)$, where $\bar{\mu}\left(a_{l}\right)$ is the depth-averaged value of the effective nonlinear viscosity defined from the solution for the channel flow (Appendix B) at distance $x=a_{l}$. Use of constant viscosity is, however, not a severe simplification, because $a_{l}$ is small.

Introducing vorticity function $\xi=\operatorname{rotv}=(\partial u / \partial y)-$ $(\partial v / \partial x)=\nabla^{2} \psi$, assuming laminar flow, we then have [Talbot and Jarvis, 1984; Fletcher, 1988]

$$
\mu \frac{\partial \xi}{\partial x}=\frac{\partial p}{\partial y} ; \quad \mu \frac{\partial \xi}{\partial y}=-\frac{\partial p}{\partial x} ; \quad \xi=\nabla^{2} \psi
$$

The upper surface of the fluid, streamline $\psi=0$, is taken to be free of shear stresses, which leads to following conditions: $p \cos 2 \alpha=2 \mu \partial^{2} \psi / \partial y^{\prime} \partial x ; p \sin 2 \alpha=\mu\left(\partial^{2} \psi / \partial x^{2}-\right.$ $\partial^{2} \psi / \partial y^{\prime 2}$ ), where $\alpha$ is the slope of the surface (positive downward). The symmetry of the flow requires $\psi\left(-x, y^{\prime}\right)=-\psi(x$, $\left.y^{\prime}\right)$.

The general solution in dimensionless variables [Talbot and Jarvis, 1984]: $X=h_{\text {max }} x^{\prime} ; Y=h(0) y^{\prime} ; p=\left(\mu q / \pi h_{\max }{ }^{2}\right) p^{\prime}$; $\psi=(q / \pi) \psi^{\prime}$, where $h_{\max }$ is the maximum height of the free surface, is

$$
\begin{aligned}
\psi= & \tan ^{-1} X / Y+X Y /\left(X^{2}+Y^{2}\right) \\
& +\sum_{n=0}^{\infty}(-1)^{n}(n+1) Y^{2 n+2}[(2 n+2) !]^{-1 /(2 n)}(X) \\
& +\sum_{n=0}^{\infty}(-1)^{n}(n+1) Y^{2 n+3}[(2 n+3) !]^{-1} \gamma^{(2 n)}(X) \\
p= & K-\lambda Y+2\left(Y^{2}-X^{2}\right) /\left(X^{2}+Y^{2}\right)^{2} \\
& +\sum_{n=0}^{\infty}(-1)^{n} X^{2 n \cdots 1}[(2 n+1) !]^{-1} f^{(2 n+1)}(X)-G(X)
\end{aligned}
$$

$$
\begin{gathered}
+\sum_{n=0}^{\infty}(-1)^{n} Y^{2 n+2}[(2 n+2) !]^{-1} \gamma^{(2 n-1)}(X) \\
G(X)=\int_{0}^{x} \gamma(s) d s .
\end{gathered}
$$

where $f$ and $\gamma$ are expressed in cxpansion series $\left(f^{(i)}, \gamma^{(i)}\right.$ are their $j$ th derivatives), $\lambda=\pi \rho g h_{\max }^{3} / \mu q, K$ is constant; $\gamma$ and $f$ arc determined numerically because the expressions for $\psi$ and $p$ are nonlinear and cannot be solved analytically. The calculation of $\psi$ and $p$ is done on the assumption of small curvature of the upper surface which allows linear approximation of $\gamma$ and $f$, i.c., as $\gamma=\mathrm{A} X$ and $f=\mathrm{B} X$. Then the frec surface can be searched in the form of a parabolic function, e.g., $\tilde{h} \sim \mathrm{C}-$ $\mathrm{D} X^{2}$ [Talbot and Janis, 1984].

\section{Notation}

$$
\begin{aligned}
& \tau_{x x}, \tau_{x y}, \tau_{y y} \text { viscous stress components, MPa. } \\
& \sigma_{x x}, \sigma_{x y}, \sigma_{y y} \text { stress components, } \sigma=\tau-P \mathbf{I} \text {, } \\
& \mathrm{MPa} \text {. } \\
& \text { p pressure, MPa. } \\
& \text { v velocity vector, } \mathrm{mm} / \mathrm{yr} \text {. } \\
& u \text { horizontal velocity ( } x \text { component of } \\
& \text { v), } \mathrm{mm} / \mathrm{yr} \text {. } \\
& v \text { vertical velocity ( } x \text { component of } \mathbf{v} \text { ), } \\
& \mathrm{mm} / \mathrm{yr} \text {. } \\
& \mu \text { effective viscosity }\left(10^{19} \text { to } 10^{23} \mathrm{~Pa} s\right) \text {, } \\
& \text { Pas. } \\
& k \text { coefficient of mass diffusivity, } \mathrm{m}^{2} / \mathrm{yr} \text {. } \\
& d h \text { topographic uplift or subsidence, } \mathrm{m} \text {. } \\
& d u \text { tectonic uplift }(>0) \text { or subsidence } \\
& (<0), \mathrm{m} \text {. } \\
& \text { de denudation }(<0) \text { or sedimentation } \\
& (>0), \mathrm{m}, \mathrm{km} \text {. } \\
& \psi \text { stream function, } u=\partial \psi / \partial y \text {, and } \\
& v=-\partial \psi / \partial y, \mathrm{~m}^{2} / \mathrm{s} \text {. } \\
& \xi \text { vorticity function } \partial u / \partial y-\partial v / \partial x= \\
& \Delta \psi, \mathrm{s}^{-1} \text {. } \\
& \varepsilon \text { strain. } \\
& \dot{\varepsilon} \text { average strain rate }\left(\dot{\varepsilon}=\left(\frac{1}{2} \dot{\varepsilon}_{i j} \dot{\varepsilon}_{i j}\right)^{1 / 2}\right), \mathrm{s}^{-1} \text {. } \\
& q \text { flux in the ducile crust, } \mathrm{m}^{2} / \mathrm{s} \text {. } \\
& q_{e} \text { erosional flux per unit length, }\left(\mathrm{m}^{2} / \mathrm{s}\right) / \mathrm{m} \text {. } \\
& E \text { Young's modulus, } 8 \times 10^{10} \mathrm{~N} / \mathrm{m}^{2} \text {. } \\
& \nu \text { Poisson's ratio, cqual to } 0.25 \text {. } \\
& \lambda, \mu_{e} \text { Lamé's constants, } \mathrm{N} / \mathrm{m}^{2} \text {. } \\
& A^{*} \text { material constant (power law } \\
& \text { rheology), } \mathrm{Pa}^{-n} \mathrm{~s}^{-1} \text {. } \\
& n \text { stress exponent (power law rheology), } \\
& \text { equal to } 3 \text { to } 5 \text {. } \\
& H^{\text {* }} \text { activation enthalpy (power law } \\
& \text { rheology), } \mathrm{kJ} \mathrm{mol}^{-1} \text {. } \\
& R \text { gas constant, equal to } 8.314 \mathrm{~J} / \mathrm{mol} \mathrm{K} \text {. } \\
& T \text { temperature, }{ }^{\circ} \mathrm{C}, \mathrm{K} \text {. } \\
& \gamma(y) \text { depth gradient of yield stress } \gamma(y) \propto \\
& d \sigma(\varepsilon) / d y, \mathrm{~Pa} / \mathrm{m} \text {. } \\
& w \text { approximate deflection of mantle } \\
& \text { lithosphere, } \mathrm{m} \text {. }
\end{aligned}
$$




$$
\begin{aligned}
& p^{-} \text {restoring stress per unit length, } \mathrm{Pa} / \mathrm{m} \text {. } \\
& h(x, t) \text { surface topography, } \mathrm{m} \text {. } \\
& \tilde{h}(x, t) \text { upper boundary of ductile channel, } \mathrm{m} \text {. } \\
& h_{c}, T_{c} \text { Moho depth, } \mathrm{m} \text {. } \\
& h_{c 2} \text { lower boundary of ductile crustal } \\
& \text { channel }\left(h_{c 2} \leq T_{c}\right) \text {, m. } \\
& h_{c l}(x, t, w) \text { maximal mechanical thickness of the } \\
& \text { upper crust }(10-20 \mathrm{~km}), \mathrm{m} \text {. } \\
& \Delta h_{c 2}(x, t, w, u, v) \text { thickness of crustal channel, } \mathrm{m} \text {. } \\
& y_{i i} \text { depths to lithological and mechanical } \\
& \text { interfaces, } m \text {. } \\
& \rho_{c 1} \text { density of upper crust, equal to } 2650 \\
& \mathrm{~kg} / \mathrm{m}^{3} \text {. } \\
& \rho_{c 2} \text { density of lower crust, equal to } 2900 \\
& \mathrm{~kg} / \mathrm{m}^{3} \text {. } \\
& \rho_{m} \text { density of mantle, equal to } 3330 \mathrm{~kg} / \mathrm{m}^{3} \text {. } \\
& \alpha \text { inclination of upper boundary of } \\
& \text { channel }(\alpha \sim \partial \tilde{h} / \partial x) \text {. } \\
& \beta \text { inclination of lower boundary of } \\
& \text { channel }(\beta \sim \partial w / \partial x) \text {. } \\
& g \text { acceleration due to gravity, equal to } \\
& 9.8 \mathrm{~m} / \mathrm{s}^{2} \text {. } \\
& t_{a} \text { thermal age ( } \leq \text { geological age), m.y. } \\
& a \text { thermal thickness of the lithosphere, } \\
& \text { equal to } 250 \mathrm{~km} \text {. } \\
& H_{c 2} C_{c 2}^{-1} \text { radiogenic heat (lower crust), equal to } \\
& 1.7 \times 10^{-1.3}{ }^{\circ} \mathrm{K} \mathrm{s}^{-1} \text {. }
\end{aligned}
$$

Acknowledgments. E. B. Burov is greatly indebted for numerous discussions to L. Lobkovsky. G. Houseman, A. Lenardic, and D. Coblentz provided detailed and thorough reviews. We also benefited from discussions with S. Cloetingh and Geoffroy King. This work was funded via contact U4 3009361/IL and U4 5000333/VC with CEA. IPGP publication 1381

\section{References}

Ahnert, F., Functional relationships between denudation, relief and uplift in large mid-latitude drainage basins, Am. J. Sci., 268, 243-263, 1970.

Andrews, D. J., and R. C. Bucknam, Fitting degradation of shoreline scarps by a nonlinear diffusion model, J. Geophys. Res., 92, 12,85712,867, 1987.
Avouac, J.-P., Analysis of scarp profiles: Evaluation of errors in morphologic dating, J. Geophys. Res., 98, 6745-6754, 1993.

Avouac, J.-P., and P. Tapponnier, Kinematic model of active deformation in central Asia, Geophys. Res. Lett., 20, 895-898, 1993.

Avouac, J.-P., P. Tapponnier, M. Bai, H. You, and G. Wang, Active thrusting and folding along the northern Tien Shan and late Ccnozoic rotation of the Tarim relative to Dzungaria and Kazakhstan, $J$. Geophys. Res., 98, 6755-6804, 1993.

Beaumont, C., Forcland basins, Geophys. J. R. Astron. Soc., 65, 389$416,1981$.

Beaumont, C., P. Fullsack, and J. Hamitton, Erosional control of active compressional orogens, in Thrust Tectonics, edited by K. R. McClay, pp. 1-31, Chapman and I Iall, New York, 1992.

Beaumont, C., P. Fullsack, and J. Hamilton, Styles of crustal deformation in compressional orogens caused by subduction of the underlying lithosphere, Tectonophysics, 232, 119-132, 1994.

Beckman, F., Tectonic modelling of thick-skinned compressional intraplate deformation, Ph.D. thesis, Free Univ., Amsterdam, 1994.

Bird, P., Lateral extrusion of lower crust from under high topography in the isostatic limit, J. Geophys. Res., 96, 10,275-10,286, 1991.

Brace, W. F., and D. L. Kohlstedt, Limits on lithospheric stress imposed by laboratory experiments, J. Geophys. Res., 85, 6248-6252, 1980 .

Burbank, D. W., Causes of recent Fimalayan uplift deduced from deposited patterns in the Ganges basin, Nature, 357, 680-683, 1992.

Burov, E. B., The short-wavelength gravity anomalies and flexurc of the continental lithosphere (in Russian), Ph.D. thesis, Inst. of Phys. of the Earth, Acad. of Sci., Moscow, 1990.

Burov, E. B., and M. Diament, Flexure of the continental lithosphere with multilayered rheology, Geophys. J. Int., 109, 449-468, 1992.

Burov, E. B., and M. Diament, The effective elastic thickness $\left(T_{c}\right)$ of continental lithosphere: What does it really mean?, I. Geophys. Res., $100,3905-3927,1995$.

Burov, E. V., M. G. Kogan, H. Lyon-Caen, and P. Molnar, Gravity anomalies, the deep structure, and dynamic processes beneath the Tien Shan, Earth Planet. Sci. Lett., 96, 367-383, 1990.

Burov, E. B., L. I. Lobkovsky, S. Cloctingh, and A. M. Nikishin, Continental lithosphere folding in central Asia, 2, Constraints from gravity and topography, Tectonophysics, 226, 73-87, 1993.

Byerlee, J. D., Friction of rocks, Pure Appl. Geophys., 176, 615-626, 1978.

Carson, M. A., and M. J. Kirkby, Hillslope Form and Processes, 475 pp., Cambridge Univ. Press, New York, 1972.

Carter, N. I., and M. C. Tsenn, Flow properties of continental lithosphere, Tectonophysics, 36, 27-63, 1987.

Chen, Y., J.-P. Cogne, V. Courtillot, J.-P. Avouac, P. Tapponnier, E. Buffetaut, G. Wang., M. Bai, H. You, M. Li, and C. Wei, Paleomagnetic study of Mesozoic continental sediments along the northern Tien Shan (China) and heterogencous strain in central Asia, $J$. Geophys. Res., 96, 4065-4082, 1991.

Chorley, R. J., S. A. Schumm, and D. E. Sugden, Hillslopes in Geomorphology, pp. 255-339, Methuen, New York, 1984.

Colman, S. M., Rock-weathering rates as functions of time, Quat. Res., $15,50-64,1981$.

Copeland, P., and T. M. Harrison, Episodic rapid uplift in the Himalaya revealed by ${ }^{40} \mathrm{Ar} /{ }^{34} \mathrm{Ar}$ analysis of detrital $\mathrm{K}$-feldspar and muscovite, Bengal fan, Geology, 18, 354-357, 1990.

Culling, W. E. H., Analytical theory of crosion, J. Geol., 68, 336-344, 1960.

Davies, G. F., Thermomechanical crosion of the lithosphere by mantle plumcs, J. Geophys. Res., 99, 15,709-15,722, 1994

Ellis, S., P. Fullsack, and C. Beaumont, Oblique convergence of the crust driven by basal forcing: Implications for length-scales of dcformation and strain partitioning in orogens, Geophys. J. Int., 120, 24-44, 1995.

England, P. C., and G. A. Houscman, Finite strain calculations of continental deformation, 2, Comparison with the India-Asia collision zone, J. Geophys. Res., 91, 3664-3676, 1986.

England, P. C., and D. P. McKenzic, A thin viscous sheet model for continental deformation, Geophys. J. R. Astron. Soc., 73, 523-532, 1983.

England, P., and S. W. Richardson, The influence of erosion upon the mineral facies of rocks from different metamorphic environments, $J$. Geol. Soc: London, 134, 201-213, 1977.

Flcmings, P. B., and T. E. Jordan, Stratigraphic modelling of foreland basins: Interpreting thrust deformation and lithosphere rheology, Geology, 18, 430-434, 1990. 
Fletcher, C. A. J., Computational Techniques for Fluid Dynamics 2, 552 pp., Springer-Verlag, New York, 1988.

Fournier, F., Climat et Erosion: La Relation Entre l'Erosion du Sol par lEau et les Precipitations Atmosph6riques, 201 pp., Presse Univ. de France, Paris, 1960.

Goetze, C., and B. Evans, Stress and temperature in the bending lithosphere as constrained by experimental rock mechanics, Geophys. J. R. Astron. Soc., 59, 463-478, 1979.

Gossman, H., Slope modelling with changing boundary conditionsEffects of climate and lithology, Z. Geomophol, Suppl, 25, 72-88, 1976.

Gratton, J., Crustal shortening, root spreading, isostasy, and the growth of orogenic belts: A dimensional analysis, J. Geophys. Res:, 94, $15,627-15,634,1989$

Greene, M. T., Geology in the Nineteenth Century: Changing Views of a Changing World, 324 pp., Cornell Univ. Press, Ithaca, N. Y., 1982.

Gregory, K. M., and C. Chase, Tectonic and climatic significance of a late Eocene low-relicf, high-level geomorphic surface, Colorado, $J$. Geophys. Res., 99, 20,141-20,160, 1994.

I lamilion, J. M. J. Kim, and F. Waleffe, Regeneration mechanisms of near-wall turbulence structures, J. Fluid Mech., 287, 317-348, 1995.

Hanks, T. C., R. C. Buckham, K. R. LaJoie, and R. E. Wallace, Modification of wave-cut and fault-controlled landforms, J. Geophys. Res.; 89, 5771-5790, 1984.

Hansen, E. B., and M. A. Kelmanson, An integral equation justification of the boundary conditions of the driven-cavity problem, Comput. Fluids, 23(1), 225-240, 1994.

Hendrix, M. S., S. A. Graham, A. R. Caroll, E. R. Sobel, C. L. McKnight, B. J. Schulein, and \%. Wang, Sedimentary record and climatic implications of recurrent deformation in the Tien Shan: Evidence from Mesozoic strata of the north Tarim, south Junggar, and Turpan basins, northwest China, Geol. Soc. Am. Bull., 104, $53-79,1992$.

Hendrix, M. S., T. A. Dumitru, and S. A. Graham, Late Oligocenecarly Miocene unroofing in the Chinese Tian Shan: An carly cffect of the India Asia collision, Geology, 22, 487-490, 1994.

Houscman, G., and P. England, Finite strain calculations of continental deformation, 1, Method and general results for convergent zones, J. Geophys. Res., 91, 3651-3663, 1986.

Huppert, H. E., The propagation of two dimensional and axisymmetric gravity currents over à rigid horizontal surface, J. Fluid. Mech., 121, $43-58,1982$

Kaufman, P. S., and L. H. Royden, lower crustal flow in an extensional setting: Constraints from the Halloran Hlills region, eastern Mojave Desert, Calilornia, J. Geophys. Res., 99, 15,723-15,739, 1994.

King, G. C. P., and S. Ellis, The origin of large local uplift in extensional regions, Nature, 348, 689-693, 1990.

King, G. C. P., R. S. Stein, and J. B. Rundle, The growth of geological struclures by repeated earthquakes, 1. Conceptual framework, $J$. Geoplys. Res., 93, 13,307-13,318, 1988

Kirby, S. H., and A. K. Kronenberg, Rheology of the lithosphere: Selected topics, Rev. Geophys., 25, 1219-1244, 1987.

Kirkby, M. J., A two-dimensional model for slope and stream evolution, in Hillstope Processes, edited by A. D. Abrahams, pp. 203-224, Allen and Unwin, Winchester, Mass., 1986.

Kohlstedt. D. L., B. Evans, and S. J. Mackwell, Strength of the lithosphere: Constraints imposed by laboratory experiments, J. Geophys. Res., 100, 17,587-17,602, 1995.

Kruse, S., M. McNutt, J. Phipps-Morgan, and L. Royden, Lithospheric extension near lake Mead, Nevada: A model lor ductile flow in the lower crust, J. Geophy;s. Res., 96, 4435-4456, 1991.

Kusznir, N. J., The distribution of stress with depth in the lithosphere: Thermo-rheological and geodynamic constraints, Philos. Trans. $R$ Soc. London A, 337, 95-110, 1991

Kusznir, N. J., and D. H. Matthews, Deep seismic reflections and the deformational mechanics of the continental lithosphere, J. Petrol., Spec. Lithosphere Issue, 63-87, 1988.

Leeder, M. R., Denudation, vertical crustal movements and sedimentary basin infill, Geol. Rundsch., 80(2), 441-458, 1991.

l.obkovsky, L. 1., Geodynamics of Spreading and Subduction Zones, and the Two-Level Plate Tectonics, 251 pp., Nauka, Moscow, 1988.

Lobkovsky, L. I., and V. I. Kerchman, A two-level concept of plate tectonics: Application to geodynamics, Tectonophysics, 199, 343-374, 1991.

Ma, X., Lithospheric Dynamic Atlas of China, China Cartograph. Publ. House, Beijing, China, 1987.

Makeyeva, L. I., L. P. Vinnik, and S. W. Roecker, Shear-wave splitting and small scalc convection in the continental upper mantle, Nature, $358,144-147,1992$.

Masck, J. G., B. L. Isacks, T. L. Gubbels, and E. J. Fielding, Erosion and tectonics at the margins of continental plateaus, J. Geophys. Res., 99, 13,94I-13,956, 1994.

McAdoo, D. C., Martin, C. F., and S. Polouse, Seasat observations of flexure: Evidence for a strong lithosphere, Tectonophysics, 116, 209222, 1985.

Molnar, P., and Q. Deng, Faulting associated with large earthquakes and the average rate of deformation in central and eastern Asia, $J$. Geophys. Res., 89, 6203-6228, 1984.

Molnar, $P_{n}$ and $P$. England, Late Cenozoic uplift of mountain ranges and global climate change: Chicken or egg, Nature, 346, 29-34, 1990.

Molnar, P., and H. Lyon-Caen, Some simple physical aspects of the support, structure, and evolution of mountain belts, in Processes in Continental Lithospheric Deformation, Spec. Pap. (jeol. Soc. Am., $2 / 8,179-207,1988$.

Pinet, P., and M. Souriau, Continental erosion and large-scale relief, Tectonics, 7, 563-582, 1988.

Ranalli, G., Nonlinear flexure and equivalent mechanical thickness of the lithosphere, Tectonophysics, 240, 107-114, 1994.

Roecker, S. W., T. M. Sabitova, L. P. Vinnik, Y. A. Burmakov, M. I. Golvanov, R. Mamatkanova, and L. Minirova, Three-dimensional clastic wave velocity structure of the western and central Tien Shan, J. Geophys. Res., 98, 15,779-15,795, 1993.

Smith, R. B., Unificd theory of the onset of folding, boudinage and mullion structure, Geol. Soc. Am. Bull., 88, 1601-1609, 1975.

Summerfield, M. A., and N. J. Hulton, Natural control on fluvial denudation rates in major world drainage basins, J. Geophys. Res., 99, $13,871-13,883,1994$

Talbot, C. J., and R. J. Jarvis, Age, budget and dynamics of an active salt extrusion in Iran, J. Struct. Geol., 6, 521-533, 1984.

Tapponnier, P., and P. Molnar, Active faulting and Cenozoic tectonics of the Tien Shan, Mongolia, and Baykal regions, J. Geophys. Res., 84, $3425-3459,1979$.

Turcotte, D. L., and G. Schubert, Geodynamics: Applications of Continuum Physics to Geological Problems, 450 pp., John Wilcy, New York, 1982.

Vilotte, J. P., M. Daignières, and R. Madariaga, Numerical modeling of intraplate deformation: Simple mechanical models of continental collision, J. Geophys. Res., 87, 10,709-10,728, 1982.

Vinnik, L. P., and A. M. Saipbekova, Structure of the lithosphere and asthenosphere of the Tien Shan, Ann. Geophys., 2, 621-626, 1984.

Vogt, P. R., Bermuda and Applachian-Labrador rises, common hotspot processes, Geology, 19, 41-44, 1991.

Wang, J. N., B. E. Hobbs, A. Ord, T. Shimamoto, and M. Toriumi, Newtonian dislocation creep in quartzites: Implications for the rheology of the lower crust, Science, 265, 1204-1206, 1994.

Westaway, R., Evidence for dynamic coupling of surface processes with isostatic compensation in the lower crust during active extension of western Turkey, J. Geophys. Res., 99, 20,203-20,223, 1994.

Windley, B. F., M. B. Allen, C. Zhang, Z. Zhao, and G. R. Wang, Palcozoic accretion and Cenozoic redeformation of the Chinese Tien Shan range, central Asia, Geology, 18, 128-131, 1990.

Zhao, W. L., and J. Morgan, Uplift of Tibetan plateau, Tectonics, 4, $359-369,1985$.

J. P. Avouac, Laboratoire de Géophysique, Groupe Tectonique et Structures I ithosphériques, BP12, 91680, Bruyères-Lc-Châtel, France. (c-mail: avouac(oldg.bruyeres.cea.fr)

E. B. Burov, Laboratoire de Gravimétrie el Gćodynamique (J.E 335), Institut de Physique du Globe de Paris, case 89, 4 Place Jussieu, 75252 Paris Cedex 05, France. (c-mail: burov@ipgp.jussieu.ir)

(Received June 26, 1995; revised March 25, 1996; accepted $\Lambda$ pril 29, 1996.) 